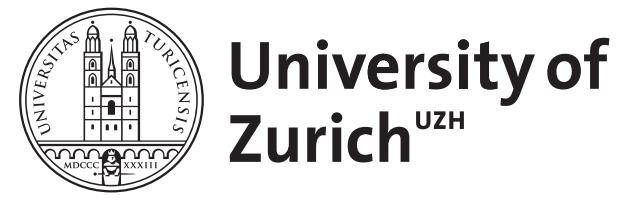

Zurich Open Repository and Archive

University of Zurich

University Library

Strickhofstrasse 39

CH-8057 Zurich

www.zora.uzh.ch

Year: 2013

\title{
Repair-driven verb movement in English locative inversion
}

\author{
Salzmann, Martin
}

DOI: https://doi.org/10.1515/9781614510796.155

Posted at the Zurich Open Repository and Archive, University of Zurich

ZORA URL: https://doi.org/10.5167/uzh-87029

Book Section

Published Version

Originally published at:

Salzmann, Martin (2013). Repair-driven verb movement in English locative inversion. In: Brandt, Patrick; Fuß, Eric. Repairs : The added value of being wrong. Boston: De Gruyter, 155-206.

DOI: https://doi.org/10.1515/9781614510796.155 


\title{
Repair-driven verb movement in English locative inversion ${ }^{1}$
}

\begin{abstract}
This paper argues that the case for English locative inversion (LI) should be re-opened. It is shown that previous accounts in terms of predicate inversion, empty expletive subjects or subject extraposition fail to account for LI with preposed adjuncts and unergative verbs. Instead it will be argued that locative inversion in English requires a rather drastic reassessment of some of the basic assumptions about English grammar. On the one hand, what has been thought of as a subject position should be re-interpreted as a more flexible position, a generalized TP. On the other, it will be argued that there is altruistic movement of the finite verb. This exceptional verb movement is analyzed as repair-driven movement that helps satisfy information structural requirements of the subject: through movement of the verb, the (unergative) subject ends up in clause-final position and can thus occupy the default focus-position. I will take these facts to argue in favor of a model of grammar that makes use of interacting and violable constraints and thus expresses the notion of repair in a very direct way.
\end{abstract}

\section{Introduction: inversions as marked constructions}

The canonical order in English sentences is Subject - T - VP. In a number of inversion constructions a non-subject appears before the finite verb (cf. Green 1985: 117 for an overview). Some of these inversion constructions like question formation, negative preposing and a few more archaic ones like Bitterly did he rue his sins can straightforwardly be analyzed as movement of an auxiliary/do from $\mathrm{T}$ to a higher head with the subject remaining in the canonical subject position Spec, TP. But next to this type there is a set of constructions that involve inversion around a full verb. The major ones (apart from minor ones such as so-inversion, cf. Culicover and Winkler 2008b) are comparative inversion (CI), quotative inversion (QI) and locative inversion (LI):

(1) a. John is much more intelligent than is the professor.

Comparative Inversion (CI)

b. “I'm freezing”, complained John. Quotative Inversion 
c. Down the hill rolled a baby carriage.

Locative Inversion

In this paper I will focus on LI (for a typological overview, cf. Salzmann 2011); for CI cf. Culicover and Winkler (2008b) and for QI cf. Collins (1997), Collins and Branigan (1997), and Suñer (2000). In 8.5 and 9.2, I will briefly come back to these other constructions. Inversions of this type are particularly important because it is far from clear how the surface structure is derived given that it is generally assumed that the finite verb does not move out of the vP in English. Most of the work on LI has consequently attempted to accommodate the construction within the established assumptions about English syntax. I will show in this paper that these attempts are empirically inadequate for at least some types of LI and will suggest instead an alternative solution that directly reflects the marked character of LI: LI involves a generalized TP and (in some instances) repair-driven verb movement to a higher head.

The paper is organized as follows: Section two introduces the predominant approach to LI which is based on the idea that LI involves a reversal of grammatical functions. In section three I present empirical arguments against such an account. Section four discusses alternative accounts of LI that address some of the questions raised in section three. Section five argues in favor of a generalized TP for English. Section six motivates verb movement. Section seven introduces the constraint set, and section eight provides an explicit analysis of LI with repair-driven verb movement as its core component. Section nine discusses open issues and section ten concludes the paper.

\section{Locative inversion in English: the "standard account"}

There has emerged over the years something like a standard account of LI that involves the following assumptions (cf. e.g. Hoekstra and Mulder 1990, Bresnan 1994, Collins 1997, den Dikken 2006, Broekhuis 2008, Hartmann 2008): LI involves a reversal of grammatical functions with the preverbal locative functioning as a subject while the postverbal agreement-triggering DP remains inside the vP. Support for this analysis comes from subject properties of the preverbal locative. In addition, the locatives have also been shown to possess certain topic properties. Finally, LI has been claimed to be restricted to unaccusative verbs that select locative arguments. In the following sections, I will reproduce some of the major empirical facts that have been put forward in favor of this position. 


\subsection{Evidence for the subject status of the preverbal locative}

The following subject properties of the locative argue for movement to Spec, TP.

\subsubsection{Raising to subject}

Fronted locatives undergo raising to subject (Bresnan 1994: 95-96):

(2) a. [Over my windowsill] seems to have crawled an entire army of ants. LI

b. [On that hill] appears to be located a cathedral.

Raising in English is restricted to grammatical subjects. Non-subjects, such as direct objects, cannot undergo raising:

(3) a. John seems _ to have come.

b. * [This book] seems John to have read _.

OBJ

Raising of locatives thus constitutes evidence in favor of the subject status of the locative.

\subsubsection{That-trace effects}

Fronted locatives trigger that-trace effects (Bresnan 1994: 97):

(4) [In which villages] do you believe [( ${ }^{*}$ that $)$ _ can be found examples of this cuisine]?

As is well-known, the that-trace effect is limited to subjects in English. Objects can be freely extracted across that:

(5) a. Who did you say (*that) _ came?

b. What did you say (that) John bought__?

OBJ

Again, preverbal locatives in LI pattern with subjects. 


\subsubsection{No do-support in wh-extraction}

Fronted locatives are questioned like subjects, i.e. without do-support (Bresnan 1994: 102):

(6) a. On which wall $\{$ hung/* did hang\} a portrait of the artist]?

b. Who $\left\{\right.$ came $/{ }^{*}$ did come $\}$ to the town?

Non-subjects require do-support and T-to-C movement of the auxiliary:

(7) a. What did John buy?

OBJ

b. * What bought John?

Again, preverbal locatives and subjects behave the same. ${ }^{2}$

\subsection{Topic properties of the preverbal locative}

Next to its subject properties, the fronted locative also has certain properties that are characteristic of topics.

\subsubsection{Referentiality}

Schachter (1992: 107-108) has pointed out that the preverbal locative has to be referential/D-linked. He presents the following contrast: While in the uninverted structure, a (non-specific) indefinite subject is possible, non-specific indefinite locatives cannot undergo LI:

(8) a. A child was found somewhere.

b. ${ }^{\star}$ Somewhere was found a child.

Similar examples are presented in Chen (2003: 86-90) who shows that non-referential PPs are not good candidates for LI (cf. also Chung and Kim 2002: 157): 3

(9) a. John went into computing.

b. * Into computing went John. 
(10) a. All good things come to an end.

b. * To an end come all good things.

(11) a. The committee came to a conclusion.

b. * To a conclusion came the committee. ${ }^{4}$

\subsubsection{The preverbal locative creates a topic island}

Bresnan (1994: 87), den Dikken (2006: 100), Rizzi and Shlonsky 2006: 344) and many others have pointed out that the locative forms a topic island, blocking any extraction from a LI, just like topics (the sentence is, of course, grammatical under a matrix construal of the wh-adverb): ${ }^{5}$

(12) a. * When did he say that into the room walked Jack?

(Rizzi and Shlonsky 2006: 344)

b. * What did to Lee Robin give?

top

(Culicover 1993: 99)

\subsubsection{LI is impossible in non-finite contexts}

Like topicalization, LI is impossible in non-finite clauses: ${ }^{6}$

(13) a. * I expect on this wall to be hung a portrait of our founder. (Bresnan 1994: 108)

b. I expect that John, you won't like

c. ${ }^{\star}$ I expect for John, you not to like _.

top

\subsubsection{LI requires overt complementizers in subordinate clauses}

If LI occurs in a subordinate clause, that clause has to be introduced by an overt complementizer. Topicalization shows the same effect:

(14) a. Mary said [*(that) under the tree sat a woman].

(Chung and Kim 2002: 148) 
b. Mary said [ ${ }^{\star}($ that $)$ the dog, the man kicked].

top

\subsubsection{Subject-aux-inversion in Ll is impossible}

Finally, like topics, fronted locatives in LI are incompatible with subject-auxiliary inversion:

(15) a. * Did on the wall hang a Mexican serape?

(Bresnan: 1994: 108)

b. * Was among the ruins found a skeleton?

(Bresnan 1994: 108)

c. * Does to Imogen, Brian ever give presents?

top (den Dikken 2006: 99)

\subsection{Argument structure restrictions}

It was noticed early on that LI is not possible with all types of verbs. It has often been claimed to be limited to unaccusatives (including passivized transitives, cf. Bresnan 1994: 77-78):

(16) a. Among the guests was sitting my friend Rose.

unaccusative

b. * Among the guests was knitting my friend Rose.

unergative

c. * Among the guests of honor seated my mother my friend Rose.

transitive

d. Among the guests of honor was seated my mother. passive

Additionally, not all unaccusatives allow LI (Levin and Rappaport-Hovav 1995: 224):

(17) a. * On the top floor of the skyscraper broke many windows.

b. * On the streets of Chicago melted a lot of snow.

c. * On backyard clotheslines dried the weekly washing. 
This asymmetry is standardly explained as follows: LI is only possible with unaccusatives taking locative arguments as in (16), but not with unaccusatives with locative adjuncts (17).

\subsection{Implementation}

The "standard account" is usually implemented as follows: The theme remains inside the vP and the locative moves across it to Spec, TP. This accounts for the subject properties. Further movement to a topic position (or adjunction to TP) captures the topic properties of the locative. ${ }^{7}$ For locative fronting to be possible, it has to be closer to Spec, TP than the subject (or at least equally close as the subject). It is usually assumed that in LI the theme and the locative are equidistant from Spec, TP because they are within the same minimal domain, i.e. within the projection of the same head, e.g. within a small-clause/PredP (e.g. Hoekstra and Mulder 1990, den Dikken 2006, Broekhuis 2008, Hartmann 2008) or within the VP (Collins 1997). ${ }^{8}$ This automatically limits the class of LI-verbs to unaccusatives with locative arguments. ${ }^{9}$ The theme remains within the SC/VP and checks case via Agree (which explains subject-verb-agreement). Since theme and locative are equidistant from Spec, TP, either can move. If the theme moves we get the canonical order, if the locative moves, the inverted order obtains. The LI-derivation can thus be sketched as follows: ${ }^{10}$
(18) a. $\left[_{\text {TорP }} \operatorname{Loc}_{\mathrm{i}}\left[_{\mathrm{TP}} \mathrm{t}_{\mathrm{i}}\left[{ }_{\mathrm{VP}} \mathrm{V}\left[\mathrm{sC}\right.\right.\right.\right.$ theme $\left.\left.\left.\left.\mathrm{t}_{\mathrm{i}}\right]\right]\right]\right]$
b. $\left[{ }_{\text {TорP }} \operatorname{Loc}_{\mathrm{i}}\left[{ }_{\mathrm{TP}} \mathrm{t}_{\mathrm{i}}\left[\mathrm{vP} \mathrm{V}+\mathrm{V}\left[{ }_{\mathrm{vP}}\right.\right.\right.\right.$ theme $\left.\left.\left.\left.\mathrm{t}_{\mathrm{v}} \mathrm{t}_{\mathrm{i}}\right]\right]\right]\right]$

A small-clause analysis has one major advantage over the VP-analysis in that it permits subsuming LI under predicate inversion: The locative predicates a property of the theme as do the DP/AP in the following examples of the subject:

(19) a. Enclosed herein is some information on our MA program.

(Chen 2003: 73)

b. The best candidate is Brian.

(den Dikken 2006: 81)

This is a welcome result since LI then no longer represents a marked construction. Rather, its properties follow from more general principles, those governing predicate inversion. 


\section{Problems with the standard account}

Even though the "standard account" can be considered the dominant approach to LI, it is confronted with serious empirical problems some of which have been known for long and some of which are discussed here for the first time. Both are related to argument structure. On the one hand, LI is possible with unergative verbs; on the other, the preverbal locatives are often non-argumental and nonpredicational.

\subsection{LI with unergatives}

Levin and Rappaport Hovav (1995: 224-227, 251-260) show that LI occurs with certain classes of unergative verbs: activity verbs, verbs of manner and motion, verbs of emission, and verbs of body-internal motion:

(20) a. [On the third floor] worked two young woman called Maryanne Thomson and Ava Brent, who ran the audio library and print room.

(L. Colwin 1990: 54 Goodbye without Leaving, cited in Birner 1995: 246)

b. [Above them] pranced the horses on the Parthenon frieze. (James, A Taste for Death, 352)

c. [On the folds of his spotless white clothing, above his left breast], glittered an enormous jewel.

(N. Lofts, Silver Nutmeg, 460)

d. ... [and in this lacey leafage] fluttered a number of grey birds with black and white stripes and long tails

(Z. Grey, Riders of the Purple Sage, 62)

As pointed out in Levin and Rappaport-Hovav (1995: 227), Birner (1995: 245-246) and Postal (2004: 343, fn. 3) such examples are by no means marginal, but rather occur quite frequently. Also, contrary to what the examples in (20) might suggest, such cases are not restricted to the literary language (cf. also Green 1982). Birner (1995: 245-246) gives some examples from contemporary newspapers one of which I reproduce here: ${ }^{11}$ 
(21) As Daley passed, thousands of onlookers cheered along the 11/2 -mile parade route down Broadway to Diversey Parkway. "Thank you," one man said to Daley as he shook the mayor's hand. [Several groups behind the mayor's car] marched police officers from Sheriff James O'Grady's parade unit.

(Chicago Tribune, 6/26/89, cited in Birner 1995: 246)

LI with unergatives is unexpected under the standard account since unergative subjects are base-generated in a higher projection than locatives, i.e. Spec, vP. Consequently, only the subject should be able to move, contrary to what is observed in (20)-(21): ${ }^{12}$

(22) $\left[{ }_{v P} \mathrm{SU} v+\mathrm{V}\left[{ }_{\mathrm{vP}} \mathrm{t}_{\mathrm{V}} \mathrm{Loc}\right]\right]$

Note also that it is unlikely that the locatives in these examples are part of the verb's argument structure. This directly leads us to the second problem.

\subsection{LI with adjuncts}

Even more problematic for the "standard account" is the hitherto largely unnoticed fact that LI is also possible with adjuncts. This includes locative adjuncts as in the following examples:

(23) a. [Next door, to the east], decays Ablett Village. (Levin and Rappaport Hovav 1995: 235)

b. [Beside it] sparkles the community pool. (Chen 2003: 56, from Vanity Fair 8/01: 57)

But one also finds inversion with adjuncts expressing various kinds of relations, such as temporal, comitative, consequential, reason, and instrumental relations as well as non-finite VPs functioning as secondary predicates: ${ }^{13}$

(24) a. [Soon after] began the busy and important part of Swift's life. (Chen 2003: 41)

b. [Yesterday] came a new idea: compensation for terrorism suspects who turn out to have been locked up without good cause.

(The Guardian, Thursday June 12, 2008, Editorial) 
c. [With the inspector] came a strange-looking man, wearing a grey coat and holding a large briefcase in his left hand.

(Levin and Rappaport 1995: 301, fn.1)

d. [With talent] comes responsibility. (clown in Woody Allen's Shadows and Fog)

e. Just about nine years ago, a meeting occurred at James Madison University, attended by William E. Dugger, Kendall Starkweather, Mark Sanders, and yours truly. The purpose of the meeting was to pursue an idea that Mark had of publishing a scholarly journal for technology education. [Thus] occurred the genesis of the Journal of Technology Education. (scholar.lib.vt.edu/ejournals/JTE/v9n2/pdf/editor.pdf)

f. [For that perverted cause] were slaughtered thousands of innocents. (Postal 2004: 17)

g. [With this pen] was written the signature that made the great change in our banking system.

(http://query.nytimes.com/gst/abstract.html?res=9A01E5DF113FE633A 25756C2A9649D946296D6CF)

h. [Crawling into the room] came the messenger from Sparta.

(Green 1985: 117)

Fronted adjuncts are completely incompatible with the "standard account" in that it is simply not possible for adjuncts to move to Spec, TP, at least not under standard assumptions: Adjuncts originate in A'-positions and therefore cannot target an A-position. It seems therefore that the "standard account" cannot capture the whole range of LI-constructions. The same holds for argument-structure-based accounts: If LI is made possible by a marked linking from argument-structure to grammatical functions, it simply cannot affect elements that are not part of a verb's argument structure.

\subsection{Still predicate inversion?}

The proponents of the predicate inversion account have addressed the problems above to some extent. Hoekstra and Mulder (1990) have argued that unergative examples like those in (20) above can be subsumed under predicate inversion: The locatives are argued to ergativize the unergative verbs (i.e. turn them into unaccusatives) and then act as predicates, predicating a property of the subject. 
The verbs would basically be copular verbs taking a small clause complement so that the standard account could be upheld. At first sight, this proposal seems quite plausible in that in some of the examples above one can replace the verb with be without drastically changing the meaning of the sentence:

(25) a. [Next door] is Abblett village.

b. [Beside it] is the community pool.

c. [Crawling into the room] is the messenger from Sparta.

However, upon closer inspection such a reanalysis does not work for many of the cases discussed in 3.1 and 3.2: First, the ergativizing effect that Hoekstra and Mulder (1990: 4) posit is motivated only on the basis of Dutch data with auxiliary switch whereby atelic unergatives become telic unaccusatives:

(26) a. Jan heeft in de sloop gesprongen.

John has in the ditch jumped

'John was jumping in the ditch.'

b. Jan is in de sloop gesprongen.

John is in the ditch jumped

'John jumped into the ditch.'

But in the cases at hand there is no change in telicity. Hoekstra and Mulder (1990: 31) do not present any evidence in favor of ergativization in the case of LI - except for the trivial fact that the examples allow LI. The possibility to rephrase the examples with be is arguably related to the presentational function of LI (Levin and Rappaport Hovav 1995: 231, Birner 1995), which implies that verbs that attract attention away from the postverbal constituent will be dispreferred in LI (cf. 9.1. below). But importantly, this is unrelated to argument structure.

Furthermore, as the examples in (24) and in Postal (2004: 343, fn. 3) show, the preposed element is not always locational and many of the adjuncts cannot be interpreted as subject-related predicates. Adverbs as in (24f/g), for instance, modify the entire event rather than predicating something of the subject. This accords with the fact that rephrasing with be is impossible:

(27) a. * [For that perverted cause] were thousands of innocents.

b. * [With this pen] is the signature that made the great change in our banking system. 
c. * YYesterday $]$ was a new idea.

d. ${ }^{*}[$ With talent $]$ is responsibility.

Finally, and most importantly, a small clause analysis predicts absence of selectional restrictions. This may be plausible for the following cases discussed in Hoekstra and Mulder (1990: 11):

(28) a. John flew into a rage.

b. The well ran dry.

c. They fell in love.

However, while the verb is clearly desemanticized in the above examples and therefore does not impose any selectional restrictions anymore, this is certainly not the case for verbs like prance, work, glitter, sparkle, decay, write, sleep late in the examples above: The verbs retain their full meaning and as a consequence impose restrictions on their subjects. In fact, as pointed out in Levin and Rappaport Hovav (1995: 230-232, 254-255, 273-274) and Green (1985: 121), LI is most acceptable if there is a close semantic connection between the verb and the subject (cf. also 9.1 below).

In conclusion, it is fair to say that there remains a substantial class of inversions that cannot be accounted for by the standard account. In the next section I will review two previous approaches that have attempted to find different solutions for such cases.

\section{Previous alternatives}

At least for the inversion constructions of the previous section an alternative solution has to be found. The fronted XP cannot be a subject at any point of the derivation. There are two alternative proposals in the literature which both analyze the fronted XP as a topic, but differ in their treatment of the subject:

(i) There is a silent expletive subject

(Coopmans 1989, Postal 2004, Bruening 2010)

(ii) There is subject extraposition

(Culicover and Levine 2001, Rizzi and Shlonsky 2006) 


\subsection{A silent expletive subject (Coopmans 1989, Postal 2004, Bruening 2010)}

Postal (1977), Coopmans (1989), Postal (2004), and more recently Bruening (2010) have argued that LI and presentational-there are basically the same construction, the only difference being that the subject position is occupied by an expletive pro in the former, but by the overt expletive there in the latter. The derivations then look as follows:

(29) a. [Down the hill $]_{1}$ pro rolled a baby-carriage _ 1 .

b. [Down the hill $]_{1}$ there rolled a baby-carriage _ 1 .

\subsubsection{Advantages}

Since fronting is topicalization, LI is correctly predicted not to be limited to locative arguments, adjuncts of all kinds can in principle be accommodated. Furthermore, the topic properties from 2.2 follow directly. Once the fronted locative is no longer a subject, the subject properties from 2.1 have to be explained differently. Raising to subject can be straightforwardly analyzed as long-distance topicalization plus raising of the expletive pro:

(30) [Over my windowsill $]_{1}$ pro $_{2}$ seems __ ${ }_{2}$ to have crawled an entire army of ants

\subsubsection{Problems}

However, this approach is confronted with several serious problems most of them having to do with asymmetries between LI and presentational-there (Bresnan 1994: 98-103). First, that-trace effects vanish under there-insertion: ${ }^{14}$

(31) [In which of these towns] do you believe that *(there) can be found a museum of Indian art?

Second, while LI does not require do-support in questions, presentational-there does (Bresnan 1994: 99-100): 
(32) a. On which wall $\left\{{ }^{\star}\right.$ did hang/hung\} a portrait of the artist?

b. On which wall $\left\{\right.$ did there hang $/{ }^{*}$ there hung\} a portrait of the artist?

Third, certain types of locative inversion (particularly with directionals) cannot occur at all with overt expletive subjects (Green 1985: 125-126, Bresnan 1994):
a. Into the room ( ${ }^{\star}$ there) ran Mother.
b. Leaning against the wall ( ${ }^{\star}$ there) stood a raggedy old man.
c. Home ( ${ }^{\star}$ there) comes John.

Fourth, the two constructions differ in their semantic restrictions on the theme (Green 1985: 126):

(34) a. Into the garden there $\mathrm{ran}{ }^{*} \mathrm{Kim} /{ }^{*}$ the cat/??the orange cat/an orange cat.

b. Into the garden ran Kim/the cat/an orange cat.

The asymmetries between LI and presentational-there thus argue against a unification of the two constructions. Furthermore, English is usually not analyzed as a semi null-subject language.

Quite apart from these asymmetries (which could perhaps be explained away, cf. Postal 2004 and Bruening 2010 for important discussion), there remains a further serious problem for this approach: While topicalization helps accommodate non-locative elements and adjuncts, it is not sufficient to describe LI with unergative verbs since the base-position of the subject is above that of the verb. Clearly, something else is needed to derive the clause-final position of the subject. ${ }^{15}$

\subsection{Subject extraposition}

Culicover and Levine (2001: 291-306) and, based on them, Rizzi and Shlonsky (2006) have argued that LI is not a uniform phenomenon, but rather comprises two different constructions. The first one, Light Inversion, corresponds to inversion with unaccusative verbs as covered by the "standard account". The second one, Heavy Inversion, involves inversion with heavy subjects and may occur with both unaccusative and unergative verbs. In that construction the locative is topi- 
calized while the subject first moves to the subject position and then undergoes extraposition:

(35) $\left[_{\mathrm{TopP}}[\text { Above them }]_{1}\left[\left[_{\mathrm{TP}}{ }_{2}\left[\mathrm{VP}_{\mathrm{vP}}{ }_{2}\right.\right.\right.\right.$ pranced $\left.\left.\_{ }_{1}\right]\right][$ the horses on the Parthenon frieze $\left.\left.]_{2}\right]\right]$.

\subsubsection{Advantages}

This accounts for several important properties of LI: The topic properties of the locative discussed in 2.2 simply follow from topicalization. More importantly, some of the subject properties also fall into place: Subject verb agreement works as in normal clauses. Raising can be reanalyzed as long-distance topicalization of the locative and raising plus extraposition of the subject:

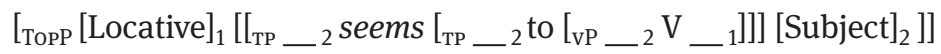

The that-trace effects are not due to locative extraction, but rather due to subject extraposition: ${ }^{16}$

(37) a. * Above them I said ( ${ }^{\star}$ that) _ 1 pranced [the horses on the P. frieze $]_{1}$.

b. $\left[{ }_{\mathrm{ToPP}}[\text { Locative }]_{1}\left[{ }_{\mathrm{TP}}\right.\right.$ I said that $\left.\left.\left[\left[_{\mathrm{TP}}{ }_{2}\left[{ }_{\mathrm{VP}}{ }_{2} \mathrm{~V}_{1}{ }_{1}\right]\right][\text { Subject }]_{2}\right]\right]\right]$

\subsubsection{Problems}

Despite its initial appeal, this approach fails on a number of aspects that cast doubts on its validity: First, subjects normally cannot extrapose in English (Collins and Branigan 1997: 6): will talk to John - the author I recommended for the literary prize

While Culicover and Levine (2001: 307-308) have little to say about this, Rizzi and Shlonsky (2006) link the restriction to nominal Fin with a loc-feature, a functional head above the subject position that satisfies the subject criterion. It attracts a locative to its Spec and makes subject extraposition possible - since the subject criterion (= EPP) is satisfied by Fin, the subject is not affected by criterial freezing and can extrapose. While technically feasible, the solution is construc- 
tion-specific and amounts to saying that subject extraposition is possible only under locative inversion. It also fails for all the non-locative XPs discussed in 3.2.

Second, since extraposition involves A'-movement, subsequent topicalization of the locative may be expected to be blocked by the Minimal Link Condition (cf. Culicover and Levine 2001: 295, fn. 13 for discussion).

Third, an account in terms of Heavy Inversion crucially relies on the heaviness of the subject. While they do indeed tend to be heavy quite often, this is certainly not a general rule. Crucially, we find light subjects with unergatives and with unaccusatives taking locative adjuncts, cf. Levin and Rappaport Hovav (1995: 255) and (23a), repeated from above:

(39) a. On the folds of his spotless white clothing, above his left breast, glittered an enormous jewel.

b. ... before the front there stretched a plateau whereon stood a flagstaff and spar, from the point of which fluttered a red ensign.

c. Next door, to the east, decays Ablett Village.

In an empirical study Holler and Hartmann (to appear) have put Culicover and Levine's (2001) claims to the test. Their results show that while heaviness generally favors structures with the subject in extraposed position, i.e. following an adverbial marking the right edge of VP, the factor verb class has no influence on the acceptability of LI as such: Inversions with light subjects are acceptable with both unaccusatives and unergatives where the subject precedes a VP-adverbial, thereby showing that the subjects cannot be extraposed. The crucial type of example is thus one like the following where the unergative subject clearly occurs within the VP:

(40) Under the stars danced numerous trolls quite cheerfully.

One can therefore conclude that LI with unergatives does not necessarily involve extraposition. This clearly undermines Culicover and Levine's (2001) two constructions approach and shows that a mechanism other than extraposition is necessary for LI with unergatives. ${ }^{17}$ 


\section{What about Spec, TP?}

In this section I will examine in detail the nature of the Spec, TP position in English and will argue that what has been thought of as an A-position that hosts subjects and expletives should be reanalyzed as a more flexible position akin to the prefield in other Germanic languages.

\subsection{The subject is low}

There is clear evidence that the EPP is not satisfied by the subject in LI. First, the subject follows non-finite verbs:

(41) a. Over my windowsill seems to have crawled [an entire army of ants]. (Bresnan 1994)

b. Out of the chaos will come [a champion]. (NBC, Chen 2003: 175)

One could potentially envisage an analysis where the verbs cluster and move to $\mathrm{C}$ as e.g. in negative inversion. However, this option can be easily shown to be unavailable since there is no verbal restructuring in English. The sequence of verbal elements can be interrupted as in the following example: ${ }^{18}$

(42) Then will probably come the other bikini, as I need it to be ready by late December ...

(seeleannknit.blogspot.com/2007/07/hello-my-name-is-leann-and-im-knit. html)

Although we have not yet determined the position of the verbal elements, this example definitely shows that the subject cannot be in Spec, TP (even if nonfinite come were in T); rather, it remains in its VP-internal base-position (assuming that there are no other positions the subject can occupy).

\section{2 "Locative" in an A'-position?}

One of the results of section 3 was that many of the fronted elements were adjuncts, some of which could not be reanalyzed as predicates inverting with the subject. Since adjuncts normally cannot move to/occupy an A-position, they are 
arguably located in an A'-position. But this suggests - having ruled out empty expletive subjects in English - that the subject position remains empty:

(43) Into the room _ came a man.

This amounts to a violation of the EPP. Normally, the EPP is taken to be inviolable in English. There have been a few proposals recently suggesting that under particular circumstances - mainly related to focus - the EPP may be violable in English, e.g. Culicover and Winkler (2008b) and Winkler and Göbbel (2008) on Comparative Inversion and Collins and Branigan (1997: 16) on Quotative Inversion. Furthermore, Postal (2004: 32) mentions a particular construction where there indeed does not seem to be a subject, viz. as-parentheticals:

(44) Lasers can, as _ is obvious, cut through stone walls.

Even though I do not want to exclude the possibility that the EPP can be violated in English I refrain from adopting that conclusion because this would leave unexplained the fact that the following type of inversion is ungrammatical (Broekhuis 2008: 271):

(45) a. * Died John.

b. * Laughed John.

Recall further that subject extraposition is impossible in English (38). These observations taken together suggest that something has to occur in front of the finite verb. This statement is not necessarily equivalent to saying that the EPP holds in English, but in what follows I will interpret it this way.

\subsection{A hint from (Mexican) Spanish - a generalized TP}

It seems therefore that despite occupying an A'-position one of the functions of the fronted locatives clearly is to avoid introducing (non Y-N-question) sentences with the finite verb. This is reminiscent of the EPP, and I will argue shortly that this is indeed their function. But this requires a new understanding of the EPP in English. A hint at a possible solution comes from Mexican Spanish as discussed in Gutierrez-Bravo (2002, 2007). He first notes that contrary to other varieties of Spanish, VSO-sentences are out: 
(46) a. ?? Compró Juan el periódico. bought John the newspaper 'John bought the newspaper.'

b. ?^ Come Pedro pan. eats Pedro bread 'Pedro eats bread.' (Gutierrez-Bravo 2007: 241-242)

Interestingly, the VSO-sentences become perfect when some other element, e.g. an adverb or an adjunct wh-phrase, occurs at the beginning:

(47) a. Ayer compró Juan el periódico. yesterday bought John the newspaper 'Yesterday, John bought the newspaper.'

b. Por qué compró Juan el periódico. why bought John the newspaper 'Why did John buy the newspaper?'

Fronting of the SU or the DO has the same effect (Gutierrez-Bravo 2002: 188):

(48) a. Juan compró el periódico. John bought the newspaper 'John bought the newspaper.'

b. El periódico lo compró Juan. the newspaper it bought John 'The newspaper, John bought it.'

The generalization that he derives from these facts is that in transitive clauses Spec, TP must be filled. He proposes a generalized TP (cf. also Zubizarreta 1998) which hosts not just (unmarked) subjects, but also topics, foci, wh-operators and negative elements. Similar observations have been made for other languages, e.g. Diesing (1990) on Yiddish and Holmberg and Nikanne (2002) on Finnish. ${ }^{19}$

I would consequently like to propose that the English TP is also of the generalized type. Crucially, the EPP now simply states that Spec, TP has to be filled. There is no reference to case, grammatical relation, A- vs. A'-status or syntactic category. Rather, the A- or A'-status of an XP in Spec, TP is determined by the factors that trigger the fronting of an XP to Spec, TP. They are discussed in section 7 where the constraint set is introduced. ${ }^{20}$ 


\section{Verb movement in LI}

\subsection{Why verb movement?}

For a subcase of LIs, those involving unergative verbs, simply fronting the locative to Spec, TP is not sufficient to derive the correct word order: Even if the subject stays low, it will still precede the verb. I therefore propose that in these cases, the verb moves across the vP-internal subject to a head between vP and C. For unaccusatives, this movement step is not necessary to derive the correct order:

(49) a. unaccusatives:

$\left[{ }_{\mathrm{vP}} \mathrm{V}\left[{ }_{\mathrm{sc}} \mathrm{SU}\right.\right.$ Loc $\left.]\right] \rightarrow\left[\mathrm{Loc}\left[{ }_{\mathrm{vp}} \mathrm{V}\left[{ }_{\mathrm{sc}} \mathrm{SU} t_{\text {Loc }}\right]\right]\right]$ Loc $\mathrm{V} \quad \mathrm{S}$ - verb mvt

b. unergatives:

$\left[\left[{ }_{\mathrm{vP}} \mathrm{SU} \mathrm{V}\right] \mathrm{Loc}\right] \rightarrow\left[\mathrm{Loc} \mathrm{V}\left[\left[_{\mathrm{vP}} \mathrm{SU} t_{V}\right] t_{\text {Loc }}\right]\right]$ Loc V S + verb mvt

Moving the verb overtly in English to some inflectional head is legitimate insofar as it takes place to check/value formal features. What is exceptional is that it takes place overtly instead of covertly/via Agree. Before turning to empirical evidence for verb movement in LI, we will briefly discuss verb movement in quotative inversion.

\subsection{Verb movement in Q।}

While the postulation of verb movement in English LI may sound very exotic, it has to be pointed out that similar proposals have been made for English QI (Collins and Branigan 1997: movement to AgrO, Collins 1997: Movement to T, Suñer 2000: movement to Asp, Roberts 2010: movement to C). The following pair shows that the subject cannot be extraposed since it precedes its complement (Collins and Branigan 1997: 4):

(50) a. "Where to" asked the driver of his passenger.

b. * “Where to" asked of his passenger the driver.

This implies that the subject is either in Spec, TP or Spec, vP. There is clear evidence, however, that the subject is in its base-position because it cannot strand a floating quantifier in QI (which is usually taken as an indication of displacement 
of the subject) while it can if the subject precedes the verb (Collins and Branigan 1997: 6):

(51) a. "We must do this again”, the guests all declared to Tony. $\rightarrow$ subject leaves all behind

b. "We must do this again”, declared all the guests to Tony.

c. * “We must do this again”, declared the guests all to Tony. $\rightarrow$ no trace of subject movement

The approaches differ with respect to the landing site of the verb. Movement to AgrO as in Collins and Branigan (1997) had to be replaced in newer accounts because of the demise of agreement projections within the minimalist program. It is mainly for this reason that Collins (1997) opted for movement to T since this was the only head between $\mathrm{v}$ and Spec, TP, the presumed landing-site of the quote (additionally, this movement was argued to lead to a spec-head-configuration in which the quote could be licensed). Movement to $\mathrm{C}$ was not considered a possibility because QI is degraded with nominative pronouns, which are normally taken to occupy Spec, TP (Suñer 2000: 533):

* "I'd like some more", requested he from his friend.

Roberts (2010, chapter 4.1.3) does argue in favor of movement to C on the following grounds: First, he considers examples like (52) grammatical (though archaic) and presents examples where the verb precedes there, which is also usually taken to occur in Spec, TP:

(53) ?? "Never!" cried there a strange man.

Suñer (2000: 549, 559) argues for movement to Asp (the projection related to outer aspect), partly based on data like (52) and the empirical generalization that QI is impossible with compound tenses (cf. also Collins and Branigan 1997: 13 and Roberts 2010: chapter 4.1.3):

(54) “I don't love you anymore”, said/*had said $/{ }^{*}$ was saying the little kid.

She assumes that Asp is occupied by aspectual auxiliaries in compound tenses (what is probably meant is that Asp is the base-position for auxiliaries; they move on to T); as a consequence, verb movement and thus QI is no longer possible; in simple tenses, however, Asp is a possible landing site for verb movement. ${ }^{21}$ 


\subsection{Positional evidence for verb movement in LI: adverb placement}

As in QI, verb movement seems to be the only possibility to derive the correct word order in LI with unergatives. Before determining the exact landing site of the verb, I will present some additional empirical evidence in favor of verb movement.

Adverb placement is a handy diagnostic for the surface position of verbs crosslinguistically. When browsing the internet, one can come across a surprisingly large number of cases of inversion where the verb (an unaccusative verb in the following examples) precedes an adverb that is normally taken to mark the vP-/VP-boundary:

(55) And as contemporary literary critics (among others) have shown, [with interpretation] comes often uncomfortable complexity. It is within this context that ...

(Sanford Levinson in Law and Social Inquiry, Vol. 16, No. 3 (Summer, 1991), pp. 643-648)

To rule out extraposition one has to test adverbs like always that do not attach to the right of the vP:

(56) [Behind Luther's Word] stood always the concept of an historical revelation which had been recorded in the Scriptures.

(books.google.de/books?isbn=1579788335

John S. Oyer - Lutheran Reformers Against Anabaptists, p. 31, found on July 17, 2012)

Unfortunately, things are not quite that straightforward. Adverbs can also precede the verb in inversion, suggesting that the reordering is optional:

(57) a. But [with success] often comes conceit, and it became obvious that major evolutions were being left out of the Web 2.0 sphere.

(blogs.sun.com/bblfish/entry/why_web_3_0)

b. Whereas most empires have involved cooperation, sometimes extensive cooperation, between the rulers and the ruled, [behind the relationship] always stood the threat, and sometimes the use, of force by the imperial power to maintain its control.

(www.nytimes.com/2006/03/05/books/chapters/0305-1st-mand.html?pagewanted=2) 


\section{c. [With fame] always comes negativity. \\ (www.thesituation.co.uk/ukartists/05/sas/sas.html)}

While (optional) verb movement is certainly an option to derive these cases, variable attachment of the adverb - to VP, vP, T', TP - derives the surface strings as well (cf. Collins 1997, Alexiadou and Anagnostopoulou 2001 for discussion). Since verb movement is necessary to derive LI with unergatives, I will also assume that verb movement takes place in the above examples. The motivation for verb-movement will be discussed in 8.3 below.

\subsection{The landing site of verb movement}

I have not yet determined the exact position to which the verb moves in LI. Given the English sentence structure, there are basically four possibilities: AgrO, Asp, $\mathrm{T}$ or $\mathrm{C}$.

Movement of the verb to $\mathrm{C}$ can be readily ruled out because the verb occurs below adverbs like probably which in turn occur below C:

(58) Then probably came the outline of the story of Dinah, which occupies some seven lines

(links.jstor.org/sici?sici=00138304(194309)10\%3A3\%3C230\%3ACFMW\%3E 2.0.CO\%3B2-0)

Even if then were in Spec, CP, it is very unlikely that came is in C since probably normally cannot be attached to C'; rather, it is attached to TP, T' or even lower (in matrix questions, probably follows the auxiliary in C).

AgrO seems to be an unattractive solution given that there has been a strong tendency to avoid agreement projections in recent years; but as we will see below, it would derive the empirical facts in a straightforward manner since it is located above the base-position of transitive and unergative subjects, which occur in Spec, vP.

Choosing between T and Asp is difficult. Asp is usually assumed to be located between Neg and v. It should therefore in principle be possible to find contexts that clearly distinguish between the two options. However, I have not been able to find any decisive evidence; this is largely due to the fact that the literature as well as corpora and the internet contain rather few examples with LI based on unergatives, which are the crucial cases for verb movement. Additionally, relevant tests like sentential negation (which would be expected to be without do-support if the verb moves to T) cannot be applied very easily because it is usually judged unac- 
ceptable in LI due to the information structural function of LI, viz. presentational focus: It makes no sense to negate the description of a scene into which a new participant is introduced (cf. 9.1):22

(59) * On my left did not sit Tom Lopez. (Chen 2003: 120)

Similarly, VP-ellipsis is ungrammatical with LI, cf. Bruening (2010: 63-64).

As with QI, one might try to use the compatibility with compound tenses as evidence. Unfortunately, the empirical situation is unclear. LI with unaccusatives is compatible with compound tenses, cf. e.g. Culicover and Winkler (2008b: 653):

(60) a. Into the room was hopping an extremely angry KANGAROO.

b. Near Robin on the bench were sitting several half-empty boxes of Chinese TAKEOUT.

c. Then, in will walk ROBIN, and scare the living daylights out of the CLASS.

As for unergatives, I have only been able to find examples with the future auxiliary, cf. Culicover and Levine (2001: e.302):

\section{(61) From this pulpit I believe will preach ROBIN.}

Whether unergatives are also compatible with present or perfect auxiliaries remains to be established empirically. The difference between will and be/have may actually be relevant for the analysis: It is often distinguished between auxiliaries that are directly inserted into $\mathrm{T}$ (will and modals with wide scope) and those that move there from a lower position (have, be and modals with narrow scope like need). Suppose first that only auxiliaries that are directly inserted into $\mathrm{T}$ are compatible with LI based on unergatives (as in (61)). In that case, Suñer's analysis proposed for QI could be adapted for LI: There would be an Asp-projection in both simple and compound tenses. In simple tenses, the unergative verb can move to Asp. In compound tenses, it could do so only if the auxiliary is directly inserted into T; however, if it is merged in Asp (as with be and have), verb movement would be blocked. If, however, LI based on unergatives is compatible with present and perfect auxiliaries, a different solution would be necessary. In fact, under a clause-structure with agreement projections (or at least AgrO) and a separate base-position for auxiliaries, such facts could be straightforwardly accommodated: 
(62) $\left[{ }_{\mathrm{TP}} \mathrm{T}\left[_{\mathrm{AuXP}} \mathrm{Aux}\left[\right.\right.\right.$ [AGROP $_{\mathrm{AgrO}}[\mathrm{vp}$ SU V Obj]]]]

Given such a structure, the non-finite verb can always move to AgrO, irrespective of whether an auxiliary is present and whether it is base-generated in $\mathrm{T}$ or in a lower position. Furthermore, unlike with Asp, no questions arise with respect to the semantics since a pure agreement projection is involved..$^{23}$ Despite these undeniable advantages, I will continue to phrase the analysis in terms of movement to Asp, both for compatibility with more recent assumptions about phrase structure and because the empirical situation with respect to compound tenses is still in need of clarification.

This section has shown that the possibility of full verb movement in English is real, at least in certain very limited contexts. However, it has to be adequately restricted, which is the topic of section 8.2.

\section{The constraint set}

For reasons that will become clear presently, the analysis of LI in this paper is based on ranked and violable constraints as in Optimality Theory (Prince and Smolensky 1993). The fact that Spec, TP has to be filled in English is forced by the following constraint:

(63) EPP: Spec, TP has to be filled ${ }^{24}$

The properties of an XP in Spec, TP are not determined by that position but by the type of operation/constraint that leads to displacement. One such constraint states that subjects should check their case feature in a spec-head relationship with $\mathrm{T}$ (or, in Agree terminology, that Agree should be followed by internal merge):

(64) SubjectCASE: Subjects are case-licensed in Spec, TP (Costa 1998)

The consequence of this constraint is that the subject is the default constituent in Spec, TP in English. Since this constraint only refers to grammatical features, the subject will have A-properties. Other constituents can occupy Spec, TP for information structural reasons, e.g. if forced by the following constraint:

(65) TopicFirst: A (sentence) topic is the initial constituent of a verbal extended projection

(Gutierrez-Bravo 2002: 191) 
This constraint forces the fronting of (sentence) topics but does not determine a particular landing site. Nothing precludes fronting a topic into Spec, TP if that position is empty as in LI. If it is occupied by the subject, the topic moves into Spec, TopP which dominates TP (or to a second specifier of TP). ${ }^{26}$ As a consequence, a topic of any grammatical relation can satisfy the EPP, as e.g. in LI. Such constituents will have A'-properties. The constraint also accounts for the position of base-generated topics as e.g. many of the adjuncts in 3.2.

TOPICFIRST can in fact be understood as a subcase of OPSPEc (Grimshaw 1997) which states that operators must appear in specifier positions. Different operators will be subject to somewhat different requirements, depending on their scope. A wh-phrase, for instance, has to front to a position where it has scope over the entire proposition (Grimshaw 1997: 379). Since OPSPEC does not refer to a particular specifier, a wh-phrase may in principle also occupy a lower specifier (Grimshaw 1997: 388), a fact that will become relevant in 8.4 and 8.5 below where we will find instances where wh-phrases land in or pass through Spec, TP. Fronting of wh-phrases, topics and foci is thus essentially semantically-driven (cf. also Broekhuis 2008: 39-40). This does not mean, though, that such operations are syntactically unconstrained. Rather, they are subject to the familiar constraints on A'-movement and undergo successive-cyclic movement. ${ }^{27}$

Having a topic is, of course, not sufficient for LI to occur. Rather, inversion is only possible if the subject is independently forced to stay low, which I take to be the result of the following interface constraint:

(66) AlignFocus: a focus marked constituent is the rightmost constituent in its clause $^{28,} 29$

As we will see in 8.4 below, this constraint has to be understood as a gradient constraint. If the subject is forced to stay low, other elements can move to spec, TP. In LI this will be possible because a topical element can satisfy the EPP.

The last constraint that will play a role is a constraint that penalizes movement of the lexical verb:

(67) NoLexMvt: Movement of the lexical verb is prohibited

This constraint is independently needed in the grammar of English where movement of the lexical verb is generally blocked while auxiliaries and modals can undergo movement. This constraint will play an important role in the implementation of exceptional verb movement in LI. 


\section{Constraint interaction}

\subsection{Forcing the subject to stay low}

Constructions like LI show that being in a focus position is more important than checking case in Spec, TP. This is expressed by the following ranking:

(68) AlignFocus $\gg$ SUbJeCt CASE

This ranking accounts for the fact that the subject stays low and checks/values its case via Agree while the EPP is checked by some other element.

\subsection{Repair-driven verb movement triggered by focus alignment}

In section $6 \mathrm{I}$ argued that there is overt movement of the lexical verb in some instances of LI, especially with unergative verbs. Since this is normally not possible in English, the question arises whether this movement can be derived from independent factors or has to be stipulated (as e.g. in Collins and Branigan 1997, Collins 1997, Suñer 2000). I submit that this exceptional verb movement can be modeled quite naturally under a repair perspective:

The notion of repair has played a prominent role in Optimality Theory (cf. e.g. Müller 2000: 39-51): A phenomenon is considered a repair if a grammatical construction has certain properties that are normally, i.e. in other constructions, not tolerated by the grammar. Repairs are implemented as follows in OT: repairs violate an independently motivated constraint but still emerge as optimal because the other candidates violate an even higher ranked constraint. A famous example of a repair operation is do-support. Normally, the insertion of expletive elements like do is prohibited (cf. ${ }^{*}$ John did leave), but it becomes obligatory under sentential negation (and in a few other contexts). There are various proposals in the literature as to why do-insertion is necessary in these contexts. In the case of negation, it has been assumed that negation blocks the lowering of the inflectional features onto the verb. $D o$ is inserted as a last resort here because without lowering an even higher constraint will be violated (e.g. *STRAY AFFIX, a constraint penalizing affixes without a host). Do-insertion violates FULL-INT (full interpretation, a ban on expletives), but this violation is tolerated in this particular context because violating *STRAY AFFix (or NoLExMvT, in case the finite lexical verb moves to $\mathrm{T}$ ) is even worse. 
Heck and Müller (2000, 2007) have introduced the notion repair-driven movement. Such movement operations "are normally impossible in a language, but become possible and, in fact, obligatory if this is the only way to satisfy a highranked syntactic constraint” (Heck and Müller 2007: 98).

Since the function of verb movement is to keep the subject in clause-final position, it is straightforward to take verb movement to be triggered by focus alignment: By moving across the subject the verb allows it to occupy a focus position. This is captured by the following ranking: ${ }^{30}$

\section{ALIGNFocus $\gg$ NoLEXMvT}

To some extent, exceptional verb movement can be compared with exceptional multiple wh-movement in multiple sluicing in German: It is well-known that German does not allow overt multiple wh-movement (Heck and Müller 2007: 128):

$$
\begin{aligned}
& \text { a. }{ }^{\star} W^{2} r_{1} \text { wen }_{2} \text { hat }-1{ }^{1}{ }^{2} \text { getroffen? } \\
& \text { who whom has } \\
& \text { 'Who met whom?' }
\end{aligned}
$$

b. Wer ${ }_{1}$ hat _ 1 wen $_{2}$ getroffen? who has whom met

Under sluicing, however, this becomes possible, in fact even obligatory (Heck and Müller 2007: 131):

(71) Irgendjemand hat irgendetwas geerbt, aber der Fritz weiss nicht someone has something inherited but the Fritz knows not mehr anymore $\left[\right.$ wer $_{1}$ was $_{2} \mathrm{C}={ }_{7}=z$ geerbt hat $]$.

Here, multiple wh-movement is possible to ensure the recoverability of the second wh-phrase. Importantly, the movement of the second wh-phrase is NOT featuredriven.

Admittedly, the parallel is not perfect because overt head movement is not necessarily non-feature-driven: If, as argued in Matushansky (2006), overt headmovement follows agreement between the higher and the lower head, head movement in LI is feature-driven. What is exceptional is that movement applies where normally Agree (or covert movement) is sufficient. In the cases discussed in Heck 
and Müller (2000, 2007), however, not even an Agree relationship is taken to hold between the head of the landing site and the moved item: Wh-scrambling, successive-cyclic wh-movement, multiple wh-movement and semantically vacuous $\mathrm{QR}$ are all taken to apply without there being a probe-goal relationship. In other words, exceptional verb movement in LI is rather to be classified as a case where procrastinate (feature checking by means of Agree) is overruled (Broekhuis 2008: 42). The Ranking ALIGNFocus $>>$ NoLEXMvT can be considered a shorthand for a ranking where ALIGNFocus outranks an economy constraint disfavoring movement which in turn outranks a constraint requiring overt feature-checking of verbal features in Asp: ALIGNFocus $>{ }^{\star}$ Move $\gg \mathrm{EPP}_{\mathrm{ASP}}$. The case of verb movement in LI is thus almost parallel to object shift of pronouns in Danish (Broekhuis 2008: 41-48) where the constraint D-PRONOUN forces fronting even though object shift is normally impossible (due to ${ }^{\star} \mathrm{MovE}>\mathrm{EPP}_{(\mathrm{CASE})}$ ). This may raise the question whether the present approach adequately expresses the marked character of LI. What is different from object shift in Danish is certainly that the fronting of the verb is altruistic: Even though it will be involved in a feature checking operation, it does not undergo this movement for this very checking operation but for the subject to be able to stay in focus; apart from inversion constructions, the verb can in principle remain in its base position. This is different in Danish pronoun fronting where the fronting is, so to speak, in the interest of the pronoun itself since it is generally not licensed inside vP (for instance for prosodic reasons). In this sense, exceptional verb movement in LI is closer to repair-driven movement in Heck and Müller, which is always altruistic. ${ }^{31}$

One empirical advantage of taking verb movement in LI to involve feature checking is that this explains why verb movement does not go up to C (cf. (58)): Movement to $\mathrm{C}$ would require an attracting feature on $\mathrm{C}$. Since this is not the case in LI (there is no operator in Spec, CP), feature-driven verb movement is not possible. ${ }^{32}$

The available evidence tends to suggest that verb movement only goes up to Asp, but not up to $\mathrm{T}$ even though this would in principle be licensed since the lexical verb (or rather V+Asp) does check features with T. Given the logic of the system I take this additional step to be blocked by economy (NoLEXMvT) and because additional movement to $\mathrm{T}$ would not help further elements be in focus (on the less than innocuous assumption that there are no elements between Asp and $\mathrm{T}$ that could be the information focus of a sentence). 


\subsection{The composite ranking}

To derive the LI facts, I propose the following ranking:

$$
\text { EPP }>\text { AlignFocus }>>\text { SubJeCT CASE }<>\text { NoLeXMvT }
$$

The EPP is undominated and is thus (at least in the contexts considered here) never violated. Postverbal subjects are possible because it is more important to be in a focus position than to check nominative case overtly/by internal merge (AlignFocus > SubjectCASE). Crucially, inversion is possible because some other element satisfies the EPP in LI, licensed by ToPICFIRST. The ranking of TOPICFIRST with respect to the other constraints is difficult to determine. Since ALIGNFocus is sufficient to rule out focal subjects in Spec, TP, TopICFIRST will not figure in the tableaux below where it is violated by the a-candidates. If focus is not at stake, the subject is in Spec, TP due to SuBJECT CASE. In that case we get the unmarked order. Repair-driven verb movement is possible because keeping the subject in focus overrules the ban against overt verb movement (ALIGNFocus > NoLEXMvT). This interaction will mainly be relevant for unergatives (see below for cases where verb movement applies to keep adverbials in focus). The following table shows the competition for an unaccusative verb. Here, the candidate (73c) without verb movement wins; verb movement leads to a violation of NoLEXMvT without having any repair function and is therefore blocked: ${ }^{33}$

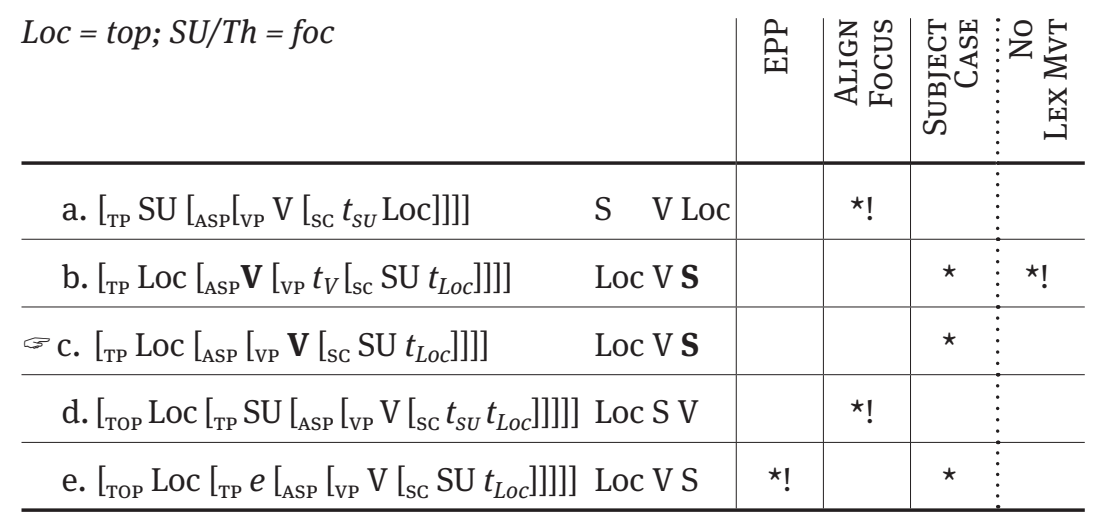


With unergative verbs, however, the candidate with verb movement wins: ${ }^{34}$

(74)

\begin{tabular}{|c|c|c|c|c|c|}
\hline$L o c=t o p ; S U / A g=f o c$ & & 盆 & 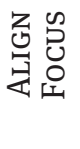 & 穿留 & 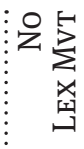 \\
\hline a. $\left[{ }_{\mathrm{TP}} \mathrm{SU}\left[\left[_{\mathrm{ASP}}\left[{ }_{\mathrm{VP}} t_{S U} \mathrm{~V}\right.\right.\right.\right.$ Loc] $\left.]\right]$ & S V Loc & & $\star$ & & \\
\hline$\approx \mathrm{b} .\left[_{\mathrm{TP}} \operatorname{Loc}\left[\left[_{\mathrm{ASP}} \mathbf{V}\left[{ }_{\mathrm{VP}} \mathrm{SU} t_{V} t_{L o c}\right]\right]\right]\right.$ & Loc V S & & & $\star$ & * \\
\hline c. $\left[{ }_{\mathrm{TP}} \operatorname{LOC}\left[{ }_{\mathrm{ASP}}\left[{ }_{\mathrm{VP}} \mathrm{SU} \mathbf{V} t_{L o c}\right]\right]\right]$ & Loc S V & & *! & * & \\
\hline d. [ ${ }_{\mathrm{TOP}} \operatorname{Loc}\left[\left[_{\mathrm{TP}} \mathrm{SU}\left[{ }_{\mathrm{ASP}}\left[{ }_{\mathrm{VP}} t_{S U} \mathrm{~V} t_{L o c}\right]\right]\right]\right]$ & Loc S V & & $\star !$ & & \\
\hline e. $\left[_{\mathrm{TOP}} \operatorname{Loc}\left[\left[_{\mathrm{TP}} e\left[_{\mathrm{ASP}}\left[{ }_{\mathrm{VP}} \mathrm{SU} \mathrm{V} t_{L o c}\right]\right]\right]\right]\right.$ & Loc S V & $\star !$ & * & * & \\
\hline
\end{tabular}

Here, a violation of NoLEXMvT is tolerated because it helps satisfy ALIGNFocus.

In section 6.3 I argued that movement of unaccusative verbs sometimes takes place, namely in those cases where the verb precedes an adverb that marks the left boundary of VP. The question is what triggers verb movement in this case. I repeat example (55) for convenience:

(75) And as contemporary literary critics (among others) have shown, [with interpretation] comes often uncomfortable complexity.

Little is known about the function of such constructions. I will provisionally propose that verb movement takes place so that the adverb can be in focus. Clearly, since the adverb is not clause-final, such examples will always incur at least one violation of ALIGNFocus. This is where the gradient nature of ALIGNFocus becomes relevant: Without verb movement there would be two violations of AlignFocus. Therefore, it is still preferred to move the verb and thereby violate NoLEXMvT to prevent a second violation of ALIGNFocus (in the previous tableaux I have ignored multiple violations of ALIGNFocUs): ${ }^{35,} 36$ 
(76)

\begin{tabular}{|c|c|c|c|c|}
\hline$L o c=t o p ; S U / t h=f o c ; A d v=f o c$ & 盆 & 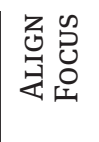 & 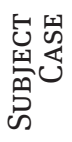 & 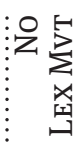 \\
\hline a. $\left[_{\mathrm{TP}} \mathbf{S U}\left[{ }_{\mathrm{ASP}} \mathbf{A d v}\left[_{\mathrm{vP}} \mathrm{V}\left[{ }_{\mathrm{sc}} t_{\mathrm{SU}}\right.\right.\right.\right.$ Loc $\left.\left.\left.]\right]\right]\right] \quad \mathbf{S}$ Adv V Loc & & $\star \star$ ! & & \\
\hline b. $\left[\left[_{\mathrm{TP}} \operatorname{Loc}\left[_{\mathrm{ASP}} \mathrm{V}\right.\right.\right.$ Adv $\left.\left.\left[_{\mathrm{VP}} t_{\mathrm{V}}\left[{ }_{\mathrm{sc}} \mathbf{S U} t_{\mathrm{Loc}}\right]\right]\right]\right]$ Loc V Adv $\mathbf{S}$ & & * & * & * \\
\hline c. $\left[{ }_{\mathrm{TP}} \operatorname{Loc}\left[_{\mathrm{ASP}} \mathbf{A d v}\left[{ }_{\mathrm{vP}} \mathrm{V}\left[_{\mathrm{sc}} \mathbf{S U} t_{\mathrm{Loc}}\right]\right]\right]\right]$ Loc Adv V $\mathbf{S}$ & & $\star \star !$ & * & \\
\hline
\end{tabular}

\subsection{What the approach captures}

The major advantages of the present account are the following: First, the generalized TP analysis helps accommodate (possibly non-locative) adjuncts. Second, the fact that the EPP is taken to hold explains the impossibility of ${ }^{*}$ Died John (cf. (45)). Third, verb movement accounts for the clause-final position of unergative subjects in LI. The approach also captures the subject and topic properties found in the construction; I will discuss these in more detail since they require some explanation.

\subsubsection{Capturing the topic properties}

Since topics are assumed to occupy Spec, TP, some of the facts can no longer be related to the structural position of topics (i.e. TopP/adjunction to TP), i.e. for instance, one can no longer rule out LI in certain contexts because the relevant structural position is lacking. This is unproblematic for the semantic properties (2.2.1) and also for the topic island effects (2.2.2) since intervention does not require a distinct structural position. But in the case of non-finite contexts (2.2.3), this becomes problematic: If the locative is a topic, nothing should prevent it from moving to Spec, TP. Fortunately, the non-applicability of LI in non-finite clauses (but recall fn. 6) can be subsumed under a more general restriction on root transformations. Even though the precise semantic conditions are still unclear (cf. Heycock 2006 for an overview), root transformations are generally said to be ruled out in non-assertive clauses (Hooper and Thomson 1973). Since non-finite clauses are non-assertive, the impossibility of $\mathrm{LI}$ is expected; the constraint ToPICFIRST simply cannot be satisfied in non-finite clauses. ${ }^{37}$ 


\subsubsection{Capturing the subject properties}

Apparent raising to subject can be reanalyzed as long-distance topicalization of the locative to the matrix Spec, TP. But the question is how exactly such sentences are derived, especially because it is not so obvious what happens to the EPP of the embedded T. There are several proposals that have argued against an EPP in non-finite clauses, cf. e.g. Grohmann et al. (2000) and Boškovic (2002), so that the problem would not arise in the first place. This would certainly work for my purposes, but in case one wants to uphold the EPP in non-finite clauses for independent reasons, it would have to be checked by the locative on its way to matrix Spec, TP - not by virtue of its being a topic, but because it is an accessible goal. This requires the locative to be closer to the intermediate Spec, TP than the subject (or at least equally close). If closeness simply depends on c-command, as in more recent Agree-based approaches, the locative will have to move to Spec, vP of the embedded clause to be closer to Spec, TP than the subject. The derivation of a raising example thus looks as follows (depending on one's assumptions, there may be an additional movement step via the edge of the vP hosting be): ${ }^{38}$

$$
\left[_{\mathrm{TP}}[\text { On that hill }]_{1} \text { appears }\left[_{\mathrm{TP}}{ }_{1} \text { to be }\left[{ }_{\mathrm{VP}}{ }_{1}{ }_{1} \text { located a cathedral __ } 1\right]\right]\right] \text {. }
$$

A similar derivation obtains if the locative just undergoes topicalization to a posi-tion above the subject, as in the following example with LI based on unergatives where the locative originates in a non-finite clause (Culicover and Levine 2001: 300):

(78) ([From this pulpit $]_{1}$ we heard preach a close associate of Cotton Mather $1]$.

Successive-cyclic movement of the locative via Spec, vP and Spec, TP will be necessary as well:

(79) [From this pulpit $]_{1}$ we heard $\left[_{\mathrm{TP}}{ }_{1} \mathrm{ASP}+\right.$ preach $\left[{ }_{\mathrm{vP}}{ }_{-1} \mathrm{t}_{\mathrm{v}}\right.$ a close associate of Cotton $\left.M .{ }_{1}\right]$ ].

As for that-trace effects, given that I do not analyze inverted locatives as subjects, they can no longer be related to a ban on subject extraction across that. This is not necessarily a drawback since it is no longer clear whether that-trace effects should be analyzed as effects that depend on the grammatical relation of the extractee. There is growing evidence that that-trace effects have a different source. Some have argued that there simply is a constraint to avoid adjacency between that and the finite verb (Kathol and Levine 1993: 213, cf. also Postal 2004, 
Bruening 2010: 52). This squares nicely with the observation that LI (like subject extraction) is subject to the adjacency effect, i.e. that that-trace effects can be ameliorated if an adverbial separates complementizer and finite verb:

(80) [On which table] were you wondering \{whether/if\} * (under certain circumstances) might have been put the books that you had bought

(Culicover 1993: 98, 104)

A similar proposal has recently been made by Salzmann et al. (to appear): We provide empirical evidence from German that the sequence complementizerfinite verb is degraded even if no extraction is involved. We then reduce thattrace effects to a phonological EPP that requires Spec, TP to be filled with phonetic material at PF. A related proposal is put forward in Bayer (2005) and Bayer and Salzmann (this volume), according to whom long wh-extraction is blocked if it takes place from a high topic position (i.e. the position of the sentence topic). Both of these alternatives account for inacceptable instances of locative preposing as in (4) and (80) (without the adverbial): There is either long A'-movement from a topic position (the locative moves via the embedded Spec, $\mathrm{TP}$, which counts as a topic position) or the embedded Spec, TP remains unfilled at PF. Furthermore, these approaches correctly predict extraction to be possible once some other element occupies the subject/topic position as in (80). The derivation of (80) is actually quite interesting: It does involve LI in the embedded clause, but it is not the locative that eventually ends up in the matrix Spec, $\mathrm{CP}$ position that undergoes inversion, but rather the sentential adverb. The locative thus extracts from a lower position (and then undergoes successive-cyclic movement):

(81) $\left[_{\mathrm{CP}}[\text { On which table }]_{1}\right.$ were you wondering $\left[_{\mathrm{CP}}{ }_{1}\{\right.$ whether/if $\}\left[_{\mathrm{TP}}\right.$ under certain circumstances might have been [ ${ }_{\mathrm{vP}}$ put the books that you had bought _ $\left.\left.\left.{ }_{1}\right]\right]\right]$ ]

The extracted locative does not function as a sentence topic and is therefore free to extract. Furthermore, the embedded Spec, TP is overtly filled at PF. This example implies that there is extraction from a locative inversion. The attentive reader will have noticed that this seems to lead to a paradoxical situation given that LI was assumed to erect a topic island (cf. 2.2.2). There is fortunately independent evidence that helps resolve the paradox: Culicover (1993: 98-100, fn. 2) points out that topic islands only obtain with fronted elements, but not with basegenerated sentential adverbs (as in (80)): ${ }^{39}$ 
(82) a. This is the tree [which $]_{1}[$ just yesterday] I had tried to dig up _ 1 with my shovel.

b. * What did [to Lee $]_{1}$ Robin _ 1 give?

What remains to be explained is how long-distance A'-movement proceeds in the absence of an overt complementizer; the following pair illustrates this for both unaccusatives and unergatives (Culicover and Levine 2001: 285, 302):

(83) [Into which room $]_{1}$ does Terry claim walked that bunch of gorillas $1 ?$

(84) [From this pulpit $]_{1}$ I believe preached a series of ravenous Tolstoy scholars

Given the two alternative explanations of that-trace effects proposed above, such examples appear problematic because there is either long A'-movement of a topic (there is no other element in the embedded clause that could assume that function) or because Spec, TP of the embedded clause remains unfilled. Here we follow Bayer (2005: 245-246) and Bayer and Salzmann (this volume) who propose that what looks like long subject extraction is actually just short extraction with the do-you-think-part functioning as a parenthetical (in the previous examples, the parentheticals would be does Terry claim and I believe). The crucial evidence for this reanalysis comes from cases where the 'do you think'-part is incompatible with the phrase structure of the sentence (for more evidence, cf. the sources mentioned above): 40

(85) Who could do you think challenge his version of the accident?

(http://query.nytimes.com/mem/archive-free/pdf?res=F10811FD3D5415738 DDDA10894DD405B8485F0D3)

The final subject property that needs to be explained is the absence of $d o$-support in questions:

(86) [On which wall] hung a portrait of the artist?

The key to an understanding of the absence of do-support in these examples is the constraint Op-SpEc (Grimshaw 1997: 388), which states that an operator must occupy a specifier position, but not necessarily Spec, CP. For subject wh-questions, fronting the subject to Spec, TP is sufficient to satisfy both the EPP and OPSPEC. In LI, ALIGNFocus forces the subject to stay low. Consequently, a locative wh-phrase 
can land in Spec, TP, thereby satisfying the EPP and OPSPEC. Structural economy will then prevent $d o$-support and projection of an additional specifier: ${ }^{41}$

(87) $\left[_{\mathrm{TP}}[\text { On which wall }]_{1}\left[_{\mathrm{vP}}\right.\right.$ hung a portrait of the artist 1]]?

\subsection{Extension to other inversion constructions}

Let me briefly discuss how this approach to inversion can be extended to other inversion constructions of English (given the complexity of these constructions and the subtle differences between them, what follows should by no means be considered a full-fledged account). Culicover and Winkler (2008b: 629) argue that in Comparative Inversion, the EPP can be violated to satisfy ALIGNFocus (note that this inversion construction involves contrastive focus, not presentational focus). They argue that the subject position remains empty in examples like the following because the subject is preceded by a non-finite auxiliary:

(88) They argue that they produced more readable and better researched reviews and editorials [than _ could have the academics under whose NAMES the papers appeared].

This would conflict with the ranking proposed above where EPP outranks ALIGNFocus and the data in (45) where a post-verbal subject is not licensed in the absence of material in Spec, TP. However, if - as is usually assumed - there is movement of an empty operator to the spec of than, it is not implausible that it moves there via Spec, TP if the subject is forced to stay low for reasons of focus (VP-ellipsis ensures that the subject is clause-final and makes verb movement across the subject unnecessary; intermediate movement to Spec, vP ensures that the operator is close enough to Spec, TP):

(89) $\left[{ }_{\mathrm{CP}} \mathrm{Op}_{1}\right.$ than $\left[{ }_{\mathrm{TP}}{ }_{1}\right.$ could have $\left[{ }_{\mathrm{vP}}{ }_{1}{ }_{1 \mathrm{vP}}\right.$ the academics $\left[{ }_{\mathrm{VP}}\right.$ produced $\left.\left.\left.\left.\left.{ }_{1}\right]\right]\right]\right]\right]$

The EPP would thus be satisfied derivationally. ${ }^{42}$

Quotative inversion is similar: The quote/the quote operator moves (via Spec, vP) to Spec, TP (and possibly continues to Spec, CP, cf. Collins 1997: 38) because the subject is forced to stay low. The verb moves to Asp (cf. Suñer 2000: 560) so that the subject is in focus: 43 
(90) a. “I'm freezing”, complained John.

b. $\left[{ }_{\mathrm{CP}}\right.$ Quote-Op ${ }_{1}\left[\mathrm{TP} \ldots{ }_{1} \mathrm{ASP}+\right.$ complained $_{2}\left[\mathrm{vP}_{\mathrm{vP}}{ }_{1}\right.$ John $\left.\left.\left._{2}{ }_{1}\right]\right]\right]$

In both cases, the EPP-checking is a side-effect of fronting triggered by A'-related features (e.g. OPSPEC). There also seem to be instances of inversion where the fronting is purely EPP-driven, viz. there-insertion and (some cases of) predicate inversion:

(91) a. There came a man into the room.

b. An excellent doctor is Brian.

(den Dikken 2006: 153)

If as in Hoekstra and Mulder (1990), den Dikken (2006), Broekhuis (2008) and Hartmann (2008) there is analyzed as a predicate, the two constructions can be unified. The theme/subject and there/the predicate are base-generated in a small clause so that both are equidistant from the subject position and both can in principle move (under the assumption, contrary to den Dikken 2006, that the small clause is not a phase). The inverted structure obtains if the subject has to be in focus. Fronting of there/the predicate is purely EPP-driven - topicality cannot be at stake (at least in those cases of predicate inversion that do not involve a definite noun phrase). Among other things, this accounts for the fact that these types of inversion can occur in non-finite clauses and that aux-inversion is possible, $\mathrm{cf}$. Hartmann (2008: 146-147), den Dikken (2006: 98-102).44, 45

\subsection{Why an approach based on inviolable constraints fails}

Let me briefly explain why I think that the present approach is superior to conceivable alternatives that do not employ violable constraints.

For instance, locative inversion could be handled by a specialized T-head that is endowed with a feature that triggers verb movement. To restrict such heads to locative inversion, they would need another feature that restricts its specifier to the elements occurring in fronted position in LI. Given the non-locative adjunct data in 3.2, a feature [+locative] will not be sufficient. But quite apart from this problem (which the present account is also confronted with to some extent, cf. 9.1 below) and from the fact that verb movement probably does not target $\mathrm{T}$, it remains unsatisfactory that the repair character of verb movement can no longer be expressed. Verb movement appears as arbitrary, the link to the information 
structural function of LI and the fact that there is an entire class of inversion constructions in English is completely lost.

One could imagine an approach based on inviolable constraints that takes information structure into account: TP would be a syncretic category hosting case and top features (Zubizarreta 1998). Subject externalization would be taken to be optional, e.g. by means of an optional EPP feature. In the presence of such a feature, we would get the non-inverted structure (SVLoc), in the absence of such a feature inversion would obtain. The trigger for verb movement in the case of unergative verbs would be more difficult to find. One could argue that Procrastinate, which is an economy constraint, can be overruled by an inviolable interface constraint, i.e. AlignFocus. In the absence of verb movement the derivation would then crash due to a violation of ALIGNFocus. The problem of inviolable constraints becomes visible, however, once there are conflicting requirements, namely when a subject is focused and there is no other element that can satisfy the EPP. In that case, inversion is impossible (Broekhuis 2008: 271):

(92) a. * Died John.

b. John died.

(92a) satisfies AlignFocus, but violates the EPP; (92b), however violates ALIGNFocUs, but satisfies the EPP. Since constraints cannot be ranked in a model based on inviolable constraints, such examples cannot be explained (cf. also Broekhuis 2008: 271 for discussion). Rather, constraints must be violable and ranked. Under the ranking EPP >> ALIGNFocUs, the correct result can be derived quite easily: 46

\begin{tabular}{|c|c|c|c|c|c|}
\hline (93) $S U /$ Agent $=$ foc & & EPP & $\begin{array}{l}\text { ALIGN } \\
\text { FocUS }\end{array}$ & $\begin{array}{l}\text { Subject } \\
\text { CASE }\end{array}$ & NoLexMvt \\
\hline a. $\left[{ }_{\mathrm{TP}} e \mathrm{~V}\left[{ }_{\mathrm{VP}} \mathrm{SU} \mathrm{t}_{\mathrm{V}}\right]\right]$ & V S & $\star !$ & & * & * \\
\hline b. $\left[_{\mathrm{TP}} \mathrm{SU}\left[{ }_{\mathrm{VP}} \mathrm{t}_{\mathrm{sU}} \mathrm{V}\right]\right]$ & $\mathrm{S} \mathrm{V}$ & & * & & \\
\hline
\end{tabular}




\section{Open issues}

\subsection{Overgeneration}

With the current constraint ranking, the approach overgenerates: Since all that is required to occupy Spec, TP is being a topic of some sort, nothing rules out inversion with objects:

\section{a. * That book likes John. \\ b. *John pleases this book.}

Since ALIGNFocus keeps the subject low, the object is free to satisfy the EPP (provided it is topical). But the result is ungrammatical. In fact, the overgeneration problem also obtains in the alternative approaches reviewed in section 4 since these also involve topicalization. Following Birner (1994, 1995), Levin-RappaportHovav (1995), Chen (2003) I argue that the restrictions follow from the discourse function of LI and should not be encoded syntactically. LI is always claimed to be used for presentational focus (Bresnan 1994), i.e. used for the introduction of a new referent on the scene (which may then become the topic of the next clause). This function limits both the class of elements occurring in Spec, TP as well as the types of verbs: Since a new referent is introduced on a scene, one needs an element to set the stage. This is preferably done by stage topics, which in turn are prototypically realized by locatives or temporal expressions (cf. also Landau 2010: 119). Given that the function of LI is to introduce a new referent, LI prefers those verbs that do not detract from the newness of the new referent. Birner (1995) calls these verbs "informationally light". This will, of course, favor certain unaccusatives like verbs of existence or appearance and disfavor externally caused verbs of change of state. Furthermore, this explains the virtual absence of transitive verbs from LI because they are normally not informationally light and because it is usually their direct object that introduces new information. ${ }^{47}$ As for unergatives, Levin-Rappaport-Hovav (1995: 251-260) show that they are most acceptable in LI if the verb is informationally light in this context. This is the case if verb and postverbal DP are mutually predictable, for instance if "the activity or the process that the verb describes is characteristic of the entity the verb is predicated of". This is quite obvious for the cases in (20) of which I repeat one example for convenience:

(95) [On the folds of his spotless white clothing, above his left breast], glittered an enormous jewel.

(N. Lofts, Silver Nutmeg, 460) 
To glitter is a characteristic of jewels, and in this combination the verb is informationally light (but see Landau 2010: 122-123 for critical discussion). Admittedly, this may not be the entire story: It is not always fully clear what is meant by presentational and whether all instances of LI can be reduced to this function: Green (1980) gives a large list of functions of inversion, Birner (1994) summarizes the function of LI as "linking relatively unfamiliar information to the prior context via the clause-initial placement of information which is relatively familiar", a generalization that is criticized by Chen (2003: 11-32). ${ }^{48}$ Related to this is the question whether all fronted elements are really stage topics. For the majority of cases, this is arguably correct, but for cases like (24d/f) and instances where the fronted element undergoes wh-movement (6a), this is at least questionable. Since these issues are essentially orthogonal to the goals of this paper, I will not pursue them any further here.

\subsection{Verb movement and particle verbs}

Marcel den Dikken (p.c.) has drawn my attention to the fact that an account in terms of verb movement is problematic in the light of data involving particle verbs. There are examples of both QI and LI where the focal subject follows the particle:

(96) a. "Don't drop the bricks", shouted out Trudy to Carl.

QI

(Collins and Branigan 1997: 5)

b. In the room danced around a group of freaky trolls.

(example modeled after den Dikken's examples)

Given that the particles normally do not incorporate into verbs in English, one would expect the subject to precede the particle with only the verb moving across it, contrary to fact. At least on the surface, the LI example seems to suggest an extraposition account (while the data in (96a) with the PP-object in its baseposition show that this cannot be correct for QI). But since extraposition of unergative and transitive subjects is normally taken to be impossible, this seems to be an undesirable solution. However, under the repair-perspective taken here, one could imagine an analysis where extraposition is exceptionally possible to satisfy ALIGNFocus, i.e. one would be dealing with repair-driven extraposition that is exceptionally possible because it would help satisfy the higher-ranking constraint AlignFocus. Examples like (38) with extraposition from the subject position could still be ruled out since EPP outranks ALIGNFocus. More gener- 
ally, repair-driven extraposition could thus replace repair-driven verb movement in the analysis of LI. I will not pursue this option here because i) extraposition generally does not work for QI (recall 6.2), ii) because unergative subjects do not always satisfy the prosodic conditions for extraposition (recall 4.2.2) and iii) because it seems unattractive to come up with two completely different solutions for the two inversion constructions. Rather, I will tentatively assume that if the repair approach advocated here is pushed to the limit, one could imagine particle incorporation taking place exceptionally in LI/QI to guarantee that the subject remains in focus; this would be possible if ALIGNFocus outranks a high-ranked constraint banning incorporation. This would be another case of repair-driven movement, but in this case it would be an instance of non-feature-driven head movement and thus the same kind of repair-driven movement as in Heck and Müller (2000, 2007). Incorporation of the particle is in fact the solution offered in Collins and Branigan (1997). In their account, incorporation has to be stipulated while in the present account it can be made to follow from a more general principle. The viability of an incorporation approach depends on whether the sequence verb + particle can be interrupted by an adverb. Collins and Branigan (1997: 5) claim that it cannot, but mention that such examples are judged grammatical by a reviewer. Roberts (2010: chapter 4.1.3) also claims that the sequence verbparticle can marginally be broken up. Since a full investigation of these empirical facts is beyond the scope of this paper, I have to leave this for future research.

\section{Conclusion}

In this paper I have argued that the analysis of English locative inversion requires a reassessment of important aspects of English syntax. The hitherto little-noticed fact that LI is possible with (possibly non-locative) adjuncts has lead to the reanalysis of the subject position Spec, TP as a generalized TP, a position that is not only targeted by subjects but can also host topics. In LI, Spec, TP can be filled by a non-subject because the subject is independently forced to stay low for reasons of focus. Adjuncts could also be accommodated if they do not target the subject position and the EPP is satisfied either by a null subject or derivationally before subject extraposition as in some alternative approaches. However, it is shown that such alternatives cannot account for LI with unergative verbs. I have argued that the correct surface order can be obtained in these cases if the verb moves across the unergative subject. This verb movement is implemented under a repair-perspective, i.e. it can exceptionally take place to avoid the violation of an even more important constraint. In the case at hand, verb movement occurs 
to allow the subject to remain in focus. This is implemented by an Optimalitytheoretic analysis where ALIGNFocus outranks NoLEXMvT so that a violation of the ban against overt movement of the lexical verb is exceptionally tolerated. In contrast with verb-movement approaches to similar inversion constructions, verb movement does not have to be stipulated in the present account, but follows from the interaction of general, independently motivated constraints.

\section{Notes}

1 Earlier versions of this work were presented at the TIN-dag in Utrecht (February 2008), at the University of Konstanz (June 2008), at the GGS in Berlin (May 2008), at the University of Tübingen (July 2008), at the LAGB meeting in Essex (September 2008) and at the repair workshop at the DGfS Osnabrück (February 2009). I am very grateful to the audiences for comments that have lead to a significant improvement of my ideas, in particular: Patrick Brandt, Josef Bayer, Hans Broekhuis, Marcel den Dikken, Eric Fuß, Hans-Martin Gärtner, Jutta Hartmann, Sara Holler, Gereon Müller, Arthur Stepanov, Volker Struckmeier, Ralf Vogel, Susanne Winkler. Additionally, the paper has benefited from detailed comments by the anonymous reviewers and by Patrick Brandt. This work has been supported by a grant from the Swiss national Science Foundation, Nr. PBSK1--119747/1.

2 In the literature one can find additional (alleged) evidence for subjecthood, but many of the diagnostics turn out to be inconclusive, cf. Postal (2004), Bruening (2010) for discussion. As we will see in 8.4 .2 below, the diagnostics discussed in this section can also be reanalyzed.

3 A similar effect is found when the preverbal locative is wh-extracted. As pointed out in Chung and $\operatorname{Kim}(2002: 157$, fn. 17), non D-linked $w h$-locatives are not felicitous (as opposed to the D-linked one in 2.1.3 above):

(i) ?? On how many walls hung a portrait of the founder's family member?

4 Once conclusion is referential, LI becomes possible again:

(i) To the same conclusion came those who investigated and analyzed the great work of the Chinese emperor Wu.

(www.ufoarea.com/aas_chinesediscovered.html)

5 Importantly, as the example above shows, the preverbal locative blocks extraction of any constituent not just of the postverbal theme. For the latter it has often been claimed that the ban against extraction is related to the fact that it is presentationally focused: Questioning such constituents would lead to pragmatic incoherence, cf. Bresnan (1994: 87-88), den Dikken (2006: 125-126). LI would thus be parallel to presentational-there, where one finds the same effect, cf. Hartmann (2008: 145). The example in the text, however, shows that extraction is independently blocked, which follows if the preverbal locative creates a topic island. I will come back to this issue in 8.4 below.

6 Interestingly, Branigan (2000: 554) gives the following as fully grammatical:

(i) The photos [ ${ }_{\mathrm{VP}}$ showed ${ }_{\mathrm{TP}}$ behind this very hedge to have been hiding Jill and Tony $\left.\mathrm{y}_{\mathrm{i}}\right]$ during each other's trials].

This example is additionally supposed to show that covert movement (of the relevant features of the postverbal subject) can lead to new binding relationships. I do not know what causes the 
disagreement between Bresnan (1994) and Branigan (2000) and will continue to assume that LI is impossible in non-finite clauses. Furthermore, Culicover and Levine (2001: 298, ex 26; 300, ex. 31) give a few examples where inversion occurs in gerundives and non-finite complements of perception verbs:

(ii) We heard from this pulpit preach [a close associate of Cotton Mather]. Importantly, on their account, what one is dealing with here is heavy inversion, i.e. subject extraposition, cf. 4.2 below. Consequently, according to them, the locatives do not have to be analyzed as occupying Spec, TP, unlike in (i) where an extraposition analysis is unavailable. But since the distinction between light and heavy inversion will be questioned in 4.2.2, data as in (ii) may eventually be equivalent to (i).

7 Den Dikken (2006: 100-102) proposes that the locative is base-generated in topic position and that what moves is a pro-PP. Base-generation may be problematic given the following reconstruction data:

(i) Beside each other ${ }_{i}$ sat two handsome young boys . $_{i}$

(Chung and Kim 2002: 150)

See also Broekhuis (2008: 296-297) for further critical remarks on the base-generation analysis.

8 There are two competing definitions of equidistance found in the literature, the one found in chapter 3 of Chomsky (1995) and the newer one in chapter 4 of Chomsky (1995). The crucial difference is that in the earlier definition equidistance holds if the target position and the possible intervener are within the same minimal domain (adapted): $\beta$ is closer to $\tau$ than $\alpha$ unless $\beta$ is in the same minimal domain as $\tau$. This definition is insufficient for LI because the theme c-commands the locative and is not in the same minimal domain as the target position Spec, TP. Consequently, it should prevent the locative from moving to Spec, TP. Under the newer definition, equidistance also obtains if the goal and the potential intervener are within the same minimal domain (adapted): $\beta$ is closer to $\tau$ than $\alpha$ unless $\beta$ is in the same minimal domain as a) $\tau$ or b) $\alpha$. This definition works for the structures in (18) since in both cases theme and locative are within the projection of the same head.

9 This is not quite correct for the small-clause approach where it is sufficient that the locatives can be interpreted as predicates. I will come back to this in section 3.3.

10 The derivations in den Dikken (2006) and Broekhuis (2008) are somewhat more complex. In den Dikken the small clause is taken to be a relator phrase: ${ }_{R P}$ Subject [Rel [Predicate]]]. Since the RP is taken to be a phase, the predicate is blocked from moving since it is not part of the edge domain of RP. Den Dikken (2006: 113-115) proposes that the head of the relator phrase, i.e. the relator, incorporates into a linker head $F$ above the RP. This not only extends the phase up to FP, it also leads to equidistance between the subject and the predicate (movement of the relator extends the minimal domain so that it includes both the landing site and the potential intervener, viz. the subject, den Dikken adopts the older definition of equidistance). As a consequence, the predicate can move across the subject:

(i) $\left[_{F P}\right.$ predicate $_{j}\left[F+\right.$ relator $\left.\left._{i}\left[_{R P} D P t_{i} t_{j}\right]\right]\right]$

Importantly, in den Dikken's approach, the inverted and the non-inverted structure do not compete, since they are based on different numerations. The non-inverted structure does not involve an empty pro-predicate but rather a normal locative.

In Broekhuis (2008: 275, 278-281) the subject of the small clause is moved to Spec, VP (short object shift). For reasons of equidistance (Broekhuis adopts the newer definition of equidistance), the predicate itself cannot front in LI because it is not within the same minimal domain as the shifted theme. Rather, the entire remnant small clause has to front:

(ii) ${ }_{T P P}\left[{ }_{s c} t_{i} P r e d\right]_{j} T\left[{ }_{v p P} v+V\left[{ }_{v P} D P_{i} t_{v} t_{j}\right]\right]$ 
11 See Green (1982) for an overview over the uses of the different inversion constructions. LI is indeed more frequent in the literary or scholarly language, but as she points out, this is surely (at least in part) related to the various functions of locative inversion that make it particularly suited for such genres.

12 This, of course, depends on one's definition of equidistance. The subject in principle blocks movement of the locative under both definitions in $\mathrm{fn} .8$, because the two are not in the same minimal domain. However, this crucially depends on whether domain-extending head movement is adopted or not. In the earlier definition of equidistance, domain-extending movement is normally adopted while the newer version tries to derive locality effects without it. With unergative verbs, equidistance only obtains if both the newer version of equidistance and domain-extending head movement are adopted: In that case, V-to-v-movement, would extend the minimal domain to include subject and locative so that both would be equidistant from $\mathrm{Spec}$, TP. LI with unergative verbs might thus argue for a new definition of equidistance. There are also argument-structure-based accounts that have modified Bresnans's (1994) original proposal to the effect that LI with unergatives can also be derived, cf. e.g. Demuth and Mmusi (1997); interestingly, these modifications were mostly motivated by LI in Bantu languages where there is no general restriction to unaccusatives, cf. Salzmann (2011) for an overview.

Note that I have presupposed in the previous reasoning that locatives occurring with unergatives are arguments generated within the VP; however, as will be shown in the following section, there is good reason to believe that they are in fact adjuncts. If this turns out to be correct, it is quite probable that at least some of them are projected outside VP (perhaps even higher than the subject). In that case, there would be no equidistance problem even without domain-extending head-movement; however, as the next subsection will show, the adjunct status of the locative will affect movement to Spec, TP (and creates difficulties for argumentstructure-based accounts).

13 This implies that „locative“ inversion is a misnomer. Another interesting type are inversions with verbs taking abstract locatives (Postal 2004: 16-17):

(i) On this election may well depend the future of our entire planet.

(Postal 2004: 17)

(ii) Second, to this structure would apply, optionally, a rule we may call verb second. (Birner 1995: 244)

The definition of adjunct I am basing myself on here is a very traditional one. An XP is an adjunct if it does not fill any of the slots provided by the lexical meaning of a verb (predicate). This is independent of the exact semantic roles an XP bears, i.e. locatives and probably a few more of the roles found in this list can in principle act as arguments of a verb. In the examples at hand, however, this is crucially not the case. For instance, manner or instrumental adverbials can be added to any action verb, but they normally do not fill a slot provided by the verb. 14 The force of this argument depends, of course, on one's analysis of that-trace effects. Under the assumptions discussed in 8.4 below, the (un)grammaticality of (31) would not be surprising.

15 It is usually assumed that $\mathrm{LI}$ and the presentational there-construction occur with the same types of verbs. Unergatives with directional complements like walk and come are widely attested with presentational there; these can probably be reanalyzed as unaccusatives, along the lines of Hoekstra and Mulder (1990). To what extent unergatives like those discussed in 3.1 (which are not readily amenable to an unaccusative reanalysis) are acceptable with presentational there is unclear at this point; crucially, if they turn out to be acceptable, the same analytical problems as with LI obtain. See Kuno and Takami (2004), Hartmann (2008) for recent discussion. 
Cf. den Dikken (2006: 273, fn. 5) for a critical assessment.

17 Culicover and Levine (2001: 289-290, fn. 8) provide another argument for the difference between Light and Heavy Inversion. They claim that WCO effects do not obtain with Light Inversion while they do with Heavy Inversion, which thus patterns with topicalization:

(i) In no dog ${ }_{\mathrm{i}}$ 's cage hung its $\mathrm{s}_{\mathrm{i}}$ collar.

Light Inv (A-mvt)

(ii) * In no dog ${ }_{\mathrm{i}}$ 's cage was hanging on a hook its ${ }_{\mathrm{i}}$ most attractive and expensive collar.

(iii) * In no dog ${ }_{\mathrm{i}}$ 's cage its $\mathrm{S}_{\mathrm{i}}$ most attractive and expensive collar was hanging on a hook.

Heavy Inv. (A'-mvt)

top (A'-mvt)

I remain skeptical concerning the force of this argument. As the authors note themselves, the judgments are delicate. Furthermore, topicalization is normally not taken to induce WCO effects (cf. Lasnik and Stowell 1991). Finally, the deviance of the example with Heavy Inversion may be due to extraposition of the bindee to an A'-position. See also Postal (2004: 348, fn. 28) for discussion.

18 This argues against the restructuring account in Culicover and Rochemont (1990: 95) who assume V-to-I-movement. Cf. also Culicover and Levine (2001: 287) for critical discussion. 19 Anders Holmberg (p.c.) has pointed out to me that the topics found in this position in Finnish do not create topic islands. In Mexican Spanish, the blocking effect does obtain with topics but not with fronted experiencers which are taken to front because they are the highest arguments of such predicates and not because of some information structural property.

20 Crosslinguistically, the set of elements that can occur in such a flexible position varies a lot. While German permits just about everything in its flexible Spec, CP position, Finnish is more restricted in that it disallows manner and sentential adverbs. At the same time it is more liberal than English in that it allows DP topics, cf. Holmberg and Nikanne (2002). There seems to be an implicational relationships in that the possibility of DPs topics in that position implies the possibility of stage topics.

21 In Culicover and Winkler (2008a: 42, ad ex. 83), a section not contained in the published version Culicover and Winkler (2008b), the impossibility of QI in compound tenses is not linked to syntactic, but to pragmatic factors: it is simply odd to combine most of the complex tenses with a direct quote. To the extent that a complex tense is pragmatically felicitous in QI, it is also acceptable.

22 There are some exceptional cases where sentential negation is possible with LI. Such cases do not seem to have a presentational function in the narrow sense:

(i) Thunderstick is right that with success does not come class, but using Belichick as your example of that is simply a crap argument

(dcatblog.blogspot.com/2006/09/belichick-mangini-handshake.html)

Unfortunately, I have not been able to find corresponding examples with unergatives.

23 While generating gerundive and perfect participles in Asp (or moving them to Asp) is relatively straightforward, such movement is much more difficult to motivate for bare infinitives and finite verbs.

24 I thus assume a more classical EPP which cannot be reduced to an EPP-feature of a probe that requires Agree to be followed by internal merge of the goal. It is basically as in Bailyn (2004) with the important difference that in Bailyn it can only be satisfied by A-movement. The constraint EPP in this approach has more or less the same effect as $\operatorname{EPP}_{(\mathrm{phi})}$ in Broekhuis (2008), but I take the implementation of the EPP proposed here to be preferable for the following reasons: First, the assumption that predicates check phi-features with T strikes me as problematic since there never is a morphological reflex of this agreement (in present-day 
English). Second, some of the fronted constituents are not predicates. Third, we will find instances of altruistic movement to Spec, TP that do not involve any feature checking other than satisfaction of the EPP (8.4 and 8.5).

I will assume in what follows that the EPP is checked derivationally. In 8.4 I will also briefly discuss a representational alternative.

25 Constraints of this type are comparable with the so-called EPP-constraints in Broekhuis (2008). Importantly, such constraints do not imply that there is no Agree. Rather, they are intended to mean that if they are satisfied they force Agree to be followed by internal merge. If the constraint is violated, there only is Agree. Broekhuis (2008) just uses one general EPPconstraint for subject and object case checking. Since I will not be dealing with object case here, SUBJECTCASE is sufficient for my purposes.

26 A formulation of the constraint in terms of linear order is necessary to allow the topic to occupy different positions, i.e. Spec, TP or a higher position. If instead TP is analyzed as a syncretic category that hosts case and top features (cf. e.g. Zubizarreta 1998) and can project either a topic or a subject, one could use a constraint EPP $_{\text {TOPIC }}$ instead that forces topics to front to Spec, TopP. Cf. also fn. 37.

27 Constraints forcing displacement are normally counteracted by economy constraints like ${ }^{*}$ MovE. Since in LI the effects of ${ }^{*}$ Move already follow from the interface constraint to be introduced presently, it will be disregarded in what follows. Note that *Move does not play a decisive role in Broekhuis' (2008) analysis of LI either. There is no single evaluation where a violation of *Move would lead to suboptimality of a candidate.

28 They are various definitions of ALIGNFocus; I have attempted to use a definition that is as neutral as possible and can be used for general information focus and presentational focus and possibly also for contrastive focus (Culicover and Winkler 2008b), but the latter may also require movement to a position more to the left or a marked accent if left in-situ (cf. Broekhuis (2008: 44, fn. 11)).

29 Den Dikken (2006: 87-88) argues against an information structural approach to LI. See Broekhuis (2008: 299-200) for a rejoinder.

30 While repair-driven movement is triggered by syntactic constraints only in the phenomena discussed in Heck and Müller $(2000,2007)$, it is triggered by an interface constraint in LI.

31 In 9.2 below we will come across another case of exceptional head movement which is altruistic as well and in contrast to V-to-Asp-movement is arguably not feature-driven. Altruistic movement is a notion often postulated for (certain instances of) German scrambling where displacement of a phrase frequently does not take place to check features of its own, but rather to allow another phrase to be in focus. Still, scrambling also often involves fronting of presuppositional/topical material so that it cannot be considered purely altruistic (cf. e.g. Fanselow 2003 for discussion). Repair-driven verb movement in LI is thus eventually quite different from scrambling.

32 To technically rule out non-feature-driven movement, one needs a higher-ranked constraint that penalizes such movement, cf. Heck and Müller (2007). An alternative consists in adopting the Derivations and Evaluations framework by Broekhuis (2008) which only allows featuredriven movement operations.

33 Since the relative ranking of SUbJeCtCASE and NoLEXMvt cannot be determined based on the data from LI, I will assume a tie for reasons of simplicity; to avoid that candidate $b$ can emerge as optimal, the tie would have to be a conjunctive local tie, cf. Müller (2000: 212f.). I have adopted a structure for unaccusatives where the verb embeds a SC. If there were instead a vP on top of a VP (Collins 1997), there would be an instance of V-to-v movement. Following 
Broekhuis (2008: 210-211) I do not take this to be a violation of NoLEXMvT but of some other constraint penalizing head movement, e.g. *STRAYFEATURE that requires amalgamation of the formal features of functional heads with their root (Broekhuis 2008). A distinction between this type of movement and v-to-T movement is needed anyway to derive differences between Germanic languages and to explain why in languages like English only movement of the lexical verb but not of auxiliaries is blocked. This distinction has the additional advantage that the marked character of verb movement in $\mathrm{LI}$ is expressed more directly: by a single violation of NoLeXMvT.

34 For ease of representation I have omitted the VP-layer. Due to obligatory V-to-v movement, all candidates will have a violation of *STRAYFEATURE. I have put the trace of the locative inside vP, but with adjuncts as in 3.2 (cf. also fn. 12) the base-position arguably has to be posited outside vP (this also holds, of course, for adjuncts with unaccusatives).

35 I suspect that focus is also relevant for cases of verb movement like the following discussed in Chomsky (1995, chapter 4):

(i) He reads often to his children.

36 A particularly recalcitrant case are inversion constructions with a clause-final adverb, as discussed in Culicover and Levine (2001: 288, 292):

(i) Into the room walked Robin slowly.

Such examples differ from canonical examples of $\mathrm{LI}$ in that the inverted subject cannot be prosodically prominent (den Dikken 2006: 272 , fn. 2). The question then is why the subject can remain low. I must admit that I do not fully understand the information structure of this construction. It seems to be the case that the adverb is focused, and judging by the examples one can find in the literature the inverted subject also seems to have a presentational function. One can therefore argue that it is also ALIGNFocus which keeps the subject low. Moving the subject to Spec, TP would lead to an additional violation of ALIGNFocus so that leaving it in its base-position is preferred. The alternative order

(ii) Into the room walked slowly ROBIN.

requires a strong accent on Robin, arguably because it undergoes Heavy NP-shift (cf. den Dikken 2006: 127-130 on extraposition in LI). This is thus another possibility for the subject to be clause-final. Importantly, the adverb is not focused in such examples. The choice between (i) and (ii) is thus probably related to information structure. A similar case is discussed in Culicover and Rochemont (1990) and Broekhuis (2008: 288-291):

(iii) Into the room came John nude.

(iv) Into the room nude came John.

Here, the choice depends on whether the depictive is part of the focus (iii) or not (iv).

37 The necessity of an overt complementizer in embedded LI (2.2.4) and the incompatibility of aux-inversion with $\mathrm{LI}(2.2 .5)$ are more difficult to account for without reference to an additional structural layer. So far, I have been assuming that topic fronting is technically implemented without feature checking. One could, however, posit optional topic features on T to trigger fronting of the locative (or merger of certain adjuncts). Once there is such a feature on T, LI can be adequately restricted: matrix verbs can be restricted to select either complement clauses as CPs (with that) or TPs (without that); in the latter case, selection would have to be restricted to TPs without a topic feature. Similarly, a C-head specified for a yes-no question could be specified to select TPs without a topic feature. In the same vein, one could prevent LI in nonfinite contexts by a ruling out topic features on non-finite $\mathrm{T}$.

If regular topics (that precede the subject) occupy a (second) specifier of $\mathrm{T}$, the same feature-based restrictions can be used. 
Instead of pursuing a purely feature-based account, one could try to uphold a structural account within the set of assumptions made so far (that would eventually be almost indistinguishable in its empirical consequences): One could take TP to be a co-projection of T and Top, i.e. a syncretic category (Zubizarreta 1998), or, similarly, to be a matching projection (Haider 1988). In both cases, the EPP would be satisfied once one specifier is filled. The impossibility of LI in non-finite clauses would be due to the absence of a TopP layer; the impossibility of subject-auxinversion could be due to the fact that a C-head specified for [yes-no] cannot select TopPs, and the necessity of an overt complementizer with embedded LI would follow if it is assumed that verbs can select either CPs (complement clauses with that) or TPs (complement clauses without that), but not TopPs.

On the incompatibility of LI with subject-auxiliary inversion, cf. also Bruening (2010).

38 Culicover and Levine (2001: 288, 297-302) claim that "raising" and long A'-movement more generally is only possible in Heavy Inversion, but not with Light Inversion. Their argument is based on examples involving adverbs where apparently the subject has to be placed clausefinally:

(i) Into the room appeared to be walking *Robin slowly/slowly a very large caterpillar.

Since it is not obvious to me in what sense subjects in examples like (77) should count as heavy and since the basic distinction between Light and Heavy Inversion has been shown to be empirically untenable in Holler and Hartmann (to appear), I will continue to assume that there is just one type of $\mathrm{LI}$ and that long-distance A'-movement is in principle always possible. Cf. also Rizzi and Shlonsky (2006: 359, fn. 4) for clear cases of long A'-movement with a light postverbal subject.

39 According to Culicover (1993: 98, fn. 1), focal fronted elements apparently also lead to an alleviation of that-trace effects:

(i) Robin met the man who $\mathrm{i}_{\mathrm{i}}$ Leslie said that [to $\left.\mathrm{KIM}\right]_{\mathrm{j}}$ _i $_{\mathrm{i}}$ had given the money _ $\mathrm{j}_{\text {. }}$.

Why no A'-intervention obtains here, is unclear to me. Perhaps this is due to the focal nature of these „topicalized“ XPs. At any rate, the amelioration in (i) is not unexpected under accounts where that-trace effects reduce to a ban on the sequence that- $\mathrm{V}_{\text {fin }}$ or a phonological EPP (under the assumption that to Kim can occupy Spec, TP).

In contrast with the literature, Culicover and Levine (2001: 302-303) claim that no topic island obtains in LI. Extraction is only taken to be degraded in Heavy Inversion. This may be related to the claim in Culicover (1996: 453-454) that there are no topic islands at all, at least not under certain focal conditions. The degradedness is instead related to processing factors. Since a full evaluation of all these proposals is beyond the scope of this paper, I leave this for further research.

40 Note that the two alternative explanations of that-trace effects require different solutions for the data in (77) and (78). Under the approach based on a ban on topic extraction, the data are unproblematic since there are no sentence topics in non-finite clauses so that there will be no extraction from a topic position; given this, movement of the locative via Spec, TP is unproblematic. Under a phonological EPP, (77) and (78) are problematic since the embedded TP is not overtly filled at PF. Under such an approach it seems inevitable to discard the EPP for non-finite clauses.

41 In Grimshaw (1997) the operator can also be in Spec, vP if there is no material above it. Since I have posited an EPP for TP, the operator has to front at least up to TP. But in principle it would be possible to reformulate the EPP in a relational way so that it can also be satisfied if Spec, vP is occupied. The notion of EPP would then be very close to the notion of pole in Gutierrez-Bravo (2002, 2007). 
42 As the reader will have noticed, these facts are incompatible with a phonological EPP holding at surface structure.

43 Note that Collins (1997) and Suñer (2000) basically have to stipulate verb movement for these constructions while in the case at hand verb movement follows from more general principles.

44 For detailed discussion of predicate inversion, also concerning differences between the type discussed here and inversion with APs, cf. den Dikken (2006: 152-160) and den Dikken (this volume).

45 Questions arise for there-insertion with unergative verbs and more generally if a definition of closeness is adopted that solely relies on c-command. If the subject is closer than there (e.g. if there originates within VP and the subject within vP or if the subject simply c-commands there), there would first have to move to Spec, vP to be close enough to Spec, TP. It is unclear, though, what might drive this movement given that I am assuming that there-fronting is purely EPP-driven.

46 Note that the same result obtains when both subject and locative are focal. In that case, a violation of ALIGNFocus cannot be avoided, cf. Broekhuis (2008: 273).

47 Culicover and Levine (2001: 308) and Birner (1995: 243) list a number of cases with transitive verbs, but they are all idiomatic and may therefore count as informationally light. 48 Landau (2010: 125-126) argues that the notion presentational focus overgenerates and claims that $\mathrm{LI}$ is restricted by a locative feature on the preposed constituent. But as discussed extensively in this paper, the notion "locative" is insufficient, even if used in an extended sense.

\section{References}

Alexiadou, Artemis and Elena Anagnostopoulou. 2001. The subject-in-situ generalization and the role of Case in driving computations. Linguistic Inquiry 32: 193-231.

Bailyn, John Frederick. 2004. Generalized Inversion. Natural Language and Linguistic Theory 22: 1-49.

Bayer, Josef. 2005. Was beschränkt die Extraktion? Subjekt - Objekt vs. Topic - fokus. In: Franz Josef D’Avis (ed.), Deutsche Syntax: Empirie und Theorie, 233-257. Göteborg: Acta Universitatis Gothoburgensis.

Bayer, Josef and Martin Salzmann. This volume. That-trace effects and resumption. How Improper Movement can be repaired.

Birner, Betty J. 1994. Information status and word order: An analysis of English inversion. Language 70: 233-259.

Birner, Betty J. 1995. Pragmatic constraints on the verb in English inversion. Lingua 97: 233-256.

Bošković, Željko. 2002. A-movement and the EPP. Syntax 5: 167-218.

Branigan, Philip. 2000. Binding effects with covert movement. Linguistic Inquiry 31: 553-557.

Bresnan, Joan. 1994. Locative inversion and the architecture of Universal Grammar. Language 70: 72-131.

Broekhuis, Hans. 2008. Derivations and Evaluations. Berlin: Mouton de Gruyter.

Bruening, Benjamin. 2010. Language-particular syntactic rules and constraints: English locative inversion and do-support. Language 86: 43-84. 
Chen, Rong. 2003. English Inversion. Berlin: Mouton de Gruyter.

Chomsky, Noam. 1995. The Minimalist Program. Cambridge, Massachusetts: MIT Press.

Chung, Chan and Jong-Bok Kim. 2002. Lexical and constructional constraints in English locative inversion. In: Mary Andronis, Erin Debenport, Anne Pycha and Keiko Yoshimura (eds.), Proceedings of the $38^{\text {th }}$ Annual Meeting of the Chicago Linguistic Society, 145-158. Chicago Linguistics Society: Chicago

Collins, Chris. 1997. Local Economy. Cambridge, Massachusetts: MIT Press.

Collins, Chris and Phil Branigan. 1997. Quotative inversion. Natural Language and Linguistic Theory 15: 1-41.

Coopmans, Peter. 1989. Where stylistic and syntactic processes meet: Locative inversion in English. Language 65: 728-751.

Costa, Joao. 1998. Word order variation: A constraint based approach. Ph.D. dissertation, Leiden University.

Culicover, Peter. 1993. The adverb effect: evidence against ECP accounts of the that-t effect. In: Amy J. Schafer (ed.), Proceedings of the $23^{\text {rd }}$ Annual Meeting of the North East Linguistic Society, 97-110. GLSA, University of Massachusetts, Amherst.

Culicover, Peter W. 1996. On distinguishing A'-movements. Linguistic Inquiry 27: 445-463.

Culicover, Peter W. and Robert Levine. 2001. Stylistic inversion in English: A reconsideration. Natural Language and Linguistic Theory 19: 283-310.

Culicover, Peter W. and Michael Rochemont. 1990. English Focus Constructions and the Theory of Grammar. Cambridge: Cambridge University Press.

Culicover, Peter and Susanne Winkler. 2008a. English focus inversion constructions. Ms. OSU and University of Tübingen.

Culicover, Peter and Susanne Winkler. 2008b. English focus inversion. Journal of Linguistics 44: 625-658.

Demuth, Katherine, and Mmusi, Sheila. 1997. Presentational focus and thematic structure in comparative Bantu. Journal of African Languages and Linguistics 18: 1-20.

Diesing, Molly. 1990. Verb movement and the subject position in Yiddish. Natural Language and Linguistic Theory 8: 41-79.

Dikken, Marcel den. 2006. Relators and Linkers. Cambridge, Massachusetts: MIT Press.

Fanselow, Gisbert. 2003. Free constituent order: A minimalist interface account. Folia Linguistica 37: 191-232.

Green, Georgia M. 1980. Some wherefores of English inversion. Language 56: 582-601.

Green, Georgia M. 1982. Colloquial and literary uses of inversions. In: Deborah Tannen (ed.), Spoken and Written language: Exploring Orality and Literacy, 119-153. Norwood, NY: Ablex.

Green, Georgia M. 1985. The description of inversions in Generalized Phrase Structure Grammar. In: Mary Niepokuj, M. VanClay, V. Nikoforidou and D. Feder (eds.), Proceedings of the $11^{\text {th }}$ Annual Meeting of the Berkeley Linguistics Society, 117-145. Berkeley, Berkeley Linguistics Society.

Grimshaw, Jane. 1997. Projection, heads, and optimality. Linguistic Inquiry 28: 373-422.

Grohmann, Kleanthes K., John Drury and Juan Carlos Castillo. 2000. No more EPP. In: Roger Billerey \& Brook Danielle Lillehaugen (eds.), Proceedings of the $19^{\text {th }}$ West Coast Conference on Formal Linguistics, 153-166. Somerville, MA: Cascadilla Press.

Gutierrez-Bravo, Rodrigo. 2002. Structural markedness and syntactic structure: A study of word order and the left periphery in Mexican Spanish. Ph.D. dissertation, University of California, Santa Cruz. 
Gutiérrez-Bravo, Rodrigo. 2007. Prominence scales and unmarked word order in Spanish. Natural Language and Linguistic Theory 25: 235-271.

Haider, Hubert. 1988. Matching projections. In: Anna Cardinaletti, Giulelmo Cinque and Giuliana Giusti (eds.), Constituent Structure. Papers from the 1987 GLOW Conference, 101-121. Dordrecht: Foris.

Hartmann, Jutta M. 2008. Expletives in Existentials. English there and German da. Utrecht: LOT. Heck, Fabian and Gereon Müller. 2000. Repair-driven movement and the local optimization of derivations. Ms, University of Leipzig.

Heck, Fabian and Gereon Müller. 2007. Derivational optimization of wh-movement. Linguistic Analysis, 33(1-2): 97-148.

Heycock, Carolyn. 2006. Embedded root phenomena. In: Martin Everaert and Henk van Riemsdijk (eds.), The Blackwell Companion to Syntax, 174-209. Oxford: Blackwell.

Hoekstra, Teun and René Mulder. 1990. Unergatives as copular verbs; locational and existential predication. The Linguistic Review 7: 1-79.

Holler, Sara, and Jutta Hartmann. To appear. Locative inversion in English: Implications of a rating study. In: Sam Featherston and Britta Stolterfoht (eds.), Empirical Approaches to Linguistic Theory: Studies in Meaning and Structure, 241-265. Berlin: Mouton de Gruyter.

Holmberg, Anders and Urpo Nikanne. 2002. Expletives, subjects, and topics in Finnish. In: Peter Svenonius (ed.), Subjects, Expletives, and the EPP, 71-105. Oxford: Oxford University Press.

Hooper, Joan and Sandra Thompson. 1973. On the applicability of root transformations. Linguistic Inquiry 4: 465-497.

Kathol, Andreas and Robert D. Levine. 1993. Inversion as a linearization effect. In: Amy J. Schafer (ed.), Proceedings of the $23^{\text {rd }}$ Annual Meeting of the North East Linguistic Society, 207-221. GLSA, University of Massachusetts, Amherst.

Kuno, Susumu, and Ken-ichi Takami. 2004. Functional Constraints in Grammar. On the Unergative-Unaccusative Distinction. Amsterdam: John Benjamins.

Landau, Idan. 2010. The Locative Syntax of Experiencers. Cambridge, Mass.: MIT Press.

Lasnik, Howard and Timothy Stowell. 1991. Weakest crossover. Linguistic Inquiry 22: 687-720.

Levin, Beth and Malka Rappaport Hovav. 1995. Unaccusativity. At the Syntax-Lexical Semantics Interface. Cambridge, Mass.: MIT Press.

Matushansky, Ora. 2006. Head movement in linguistic theory. Linguistic Inquiry 37: 69-109.

Müller, Gereon. 2000. Elemente der optimalitätstheoretischen Syntax. Tübingen: Stauffenburg.

Postal, Paul M. 1977. About a "nonargument" for raising. Linguistic Inquiry 8: 141-154.

Postal, Paul M. 2004. Skeptical Linguistic Essays. Oxford: Oxford University Press.

Prince, Alan and Paul Smolensky. 1993. Optimality Theory: Constraint interaction in Generative Grammar. Rutgers University for Cognitive Science: RuCCS Technical Report No.2.

Rizzi, Luigi and Ur Shlonsky. 2006. Satisfying the Subject Criterion by a non subject: English locative inversion and Heavy NP Shift. In: Mara Frascarelli (ed.), Phases of Interpretation, 341-361. Berlin: Mouton de Gruyter.

Roberts, Ian. 2010. Agreement and Head Movement. Clitics, Incorporation, and Defective Goals. Cambridge, Mass.: MIT Press.

Salzmann, Martin. 2011. Towards a typology of locative inversion - Bantu, perhaps Chinese and English - but beyond? Language and Linguistics Compass 5: 169-189.

Salzmann, Martin, Jana Häussler, Markus Bader and Josef Bayer. To appear. That-trace effects without traces. An experimental investigation. In: Stefan Keine and Shayne Sloggett 
(eds.), Proceedings of the $42^{\text {nd }}$ Annual Meeting of the North East Linguistic Society. GLSA, University of Massachusetts, Amherst.

Schachter, Paul. 1992. Comments on Bresnan and Kanverva's "Locative inversion in Chichewa:

A case study of factorization in grammar”. In: Timothy Stowell and EricWehrli (eds.), Syntax and the Lexicon, 103-110. New York/San Francisco/London: Academic Press.

Suñer, Margerita. 2000. The syntax of direct quotes with special reference to Spanish and English. Natural Language and Linguistic Theory 18: 525-578.

Winkler, Susanne and Edward Göbbel. 2008. Focus in comparative inversion constructions. Handout DEAL II, Leiden.

Zubizarreta, Maria Lisa. 1998. Prosody, Focus, and Word Order. Cambridge, Mass: MIT Press. 